\title{
LINCOLN

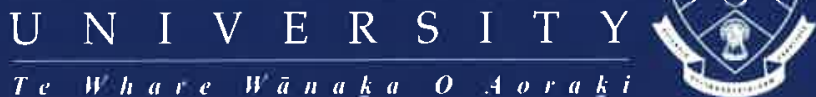

\section{Westland petrels and the hoki fishery: determining co-occurrence using satellite telemetry}

A.N.D. Freeman ${ }^{1}$, K-J. Wilson ${ }^{1}$ and D.G. Nicholls ${ }^{2}$

${ }^{1}$ Ecology and Entomology Group,

PO Box 84, Lincoln University, Canterbury, New Zealand

${ }^{2}$ Peninsula Institute of Technical and Further Education, Bonbeach Campus, Victoria 3197, Australia

Prepared for: Department of Conservation
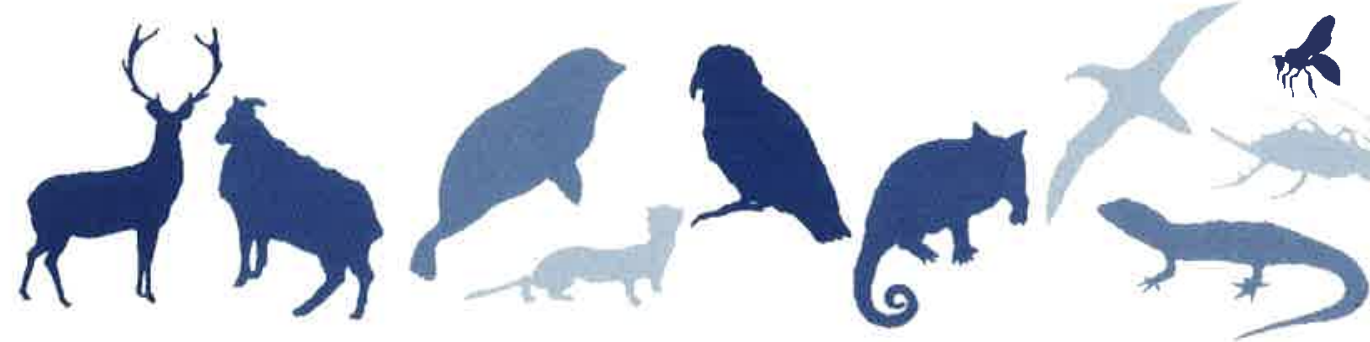

\section{Lincoln University Wildlife Management Report No.10}




\title{
WESTLAND PETRELS AND THE HOKI FISHERY: DETERMINING CO-OCCURRENCE USING SATELLITE TELEMETRY
}

\author{
A.N.D. Freeman ${ }^{1}$, K-J. Wilson ${ }^{1}$ and D.G. Nicholls ${ }^{2}$ \\ ${ }^{1}$ Ecology and Entomology Group, PO Box 84, Lincoln University \\ ${ }^{2}$ Peninsula Institute of Technical and Further Education, Bonbeach Campus
}

Prepared for:

Department of Conservation

February 1997 


\subsection{SUMMARY}

\subsection{Project}

Westland petrels were tracked by satellite and the tracks followed by the birds compared to the distribution of hoki fishing vessels. The proportion of time that Westland petrels spent in the vicinity of fishing vessels is used to assess the potential contribution of fisheries waste to the Westland petrel diet.

\subsection{Objective}

To determine the proportion of time that Westland petrels spend in the vicinity of hoki fishing vessels.

\subsection{Methods}

- Twelve Westland petrels were tracked by satellite for a total of 22 foraging trips.

- Positions of vessels in the West Coast South Island and Cook Strait fishing areas during the periods of satellite tracking were plotted in the Geographical Information System ArcView ${ }^{\circledR}$.

- The birds' foraging trips were compared with the distribution of fishing vessels and the proportion of time that they spent in the vicinity of fishing vessels was assessed.

\subsection{Results}

- Most birds which were tracked foraged over the continental shelf and slope west of the Westland petrel colony. However, two birds travelled through Cook Strait, and three birds spent considerable time inshore during their foraging trips.

- There was considerable variation in the amount of time that Westland petrels spent in the vicinity of hoki fishing vessels. Some birds spent as much as half their foraging trip near the fishing fleet, while some birds spent very little time near vessels.

\subsection{Conclusion}

Satellite tracked Westland petrels spent ample time in areas where fisheries waste could make an important contribution to their diet. Their reduced flight speed while near vessels indicates that they were scavenging there. The tracked birds did, however, forage over much wider areas than those occupied by the hoki fishing fleets. 


\subsection{INTRODUCTION}

Westland petrels Procellaria westlandica breed only near Punakaiki on the West Coast of New Zealand. About $80 \mathrm{~km}$ off shore from their colony, New Zealand's largest commercial fishery, for hoki Macruronus novaezelandiae operates from mid June to early September. This period coincides with the Westland petrel's breeding season. Waste from the hoki fishery represents a large potential food source for Westland petrels and other seabirds. Currently, in the main hoki fishing areas, around $100000 \mathrm{t}$ is caught off the West Coast, and a further $40000 \mathrm{t}$ in the Cook Strait each year and tens of thousands of tons of offal and discarded fish are discharged as waste.

The use of fisheries waste by scavenging seabirds has received increasing attention in recent years and several studies have found waste to be an important component in the diet of species which have learnt to exploit this abundant and readily available food source. For example, Jackson (1988) found that trawl offal was the dominant food by mass of the white-chinned petrel Procellaria aequinoctialis in the southern Benguela region during the non-breeding season. This interest in scavenging on fisheries waste arises from the concern expressed by some seabird biologists that if a large enough proportion of a species' population comes to depend on scavenging waste at fishing vessels, they could experience a food crisis if fishing operations altered or ceased (eg Bartle 1974, Abrams 1983).

Apparently, in the late 1950s, few Westland petrels fed on trawl waste from fishing boats, but the number feeding on the Cook Strait trawling grounds greatly increased during the 1960s (Bartle 1974). With the development of the hoki fishery in the 1970s, Westland petrels were observed feeding on fisheries waste during exploratory fishing off Greymouth (Vooren 1977). In recent years, Westland petrels have regularly been recorded scavenging behind West Coast hoki trawlers (P. Langlands pers. comm.; A.N.D. Freeman pers. obs.). Given the size of the fishery, it's proximity to the Westland petrels' breeding area, and the timing of the hoki fishing season, we considered the West Coast hoki fishery likely to be the Westland petrels' most utilised source of fisheries waste. 
It has been assumed that Westland petrels feed extensively on fisheries waste and this habit has been considered at least partly responsible for an increase in the Westland petrel population (Bartle 1985 and 1987). Feeding on fisheries waste has also been implicated in malnutrition, resulting in the feather malformation present in $20-30 \%$ of Westland petrel fledglings (J.A. Bartle unpublished data). However, until now, there have been no studies to test the assertion that fisheries waste is an important food source for Westland petrels.

The main aim of this satellite tracking programme was to determine the proportion of time that Westland petrels spend in the vicinity of hoki fishing vessels. This was achieved by comparing the birds' mapped foraging trips to the distribution of hoki vessels, and calculating the proportion of time that birds spent in proximity to the hoki fleet compared to time spent foraging elsewhere. This satellite tracking programme was complemented by diet studies and a survey of Westland petrels at sea in a wider study of the importance of fisheries waste in the diet of Westland petrels.

\subsection{METHODS}

Breeding season energy requirements are greatest during chick guarding, a period after hatching when one or other parent stays in the burrow to guard the chick (Ricklefs 1983). Scavenging on fisheries waste could be expected to be most prevalent during that time. However, very young petrel chicks suffer high mortality (Warham 1996) and we were concerned about the possibly increased chances of desertion if tracking was carried out immediately after hatching. Our satellite tracking period was therefore a compromise timed to cover the end of the guard stage and the start of the period when chicks are left on their own in the burrow. Between 11 August and 19 September 1995, three male Westland petrels were tracked by satellite for a total of six foraging trips. The details of their PTTs (Platform Transmitting Terminals) and PTT attachment and recovery are given in Freeman et al. (in prep) (see Appendix 1). Between 6 August and 3 September 1996, 4 female and 5 male Westland petrels were satellite tracked for a total of 16 foraging trips. Seven of these birds were tracked for two trips, two were tracked for one trip only. Because male Westland petrels spend more time ashore J.A. 
Bartle pers. comm., A.N.D. Freeman pers. obs.), it was easier to find males to attach PTTs to and hence we tracked fewer females than males. The dates and times of attachment and recovery of PTTs in 1996 are shown in Table 1.

Table 1. 1996 PTT deployment and recovery details.

\begin{tabular}{|c|c|c|c|c|c|c|}
\hline $\begin{array}{l}\text { Bird ID sex/ } \\
\text { flight }\end{array}$ & $\begin{array}{l}\text { Band } \\
\text { No. }\end{array}$ & PTT att & $\begin{array}{l}\text { ichment /re } \\
\text { weight }(g)\end{array}$ & ecovery & Flight start/finish & $\begin{array}{l}\text { Trip } \\
\text { (days) }\end{array}$ \\
\hline $\begin{array}{l}\text { Merlene F/1 } \\
\text { Merlene F/2 }\end{array}$ & L31707 & $13 / 8 / 96$ & $1600 \mathrm{hrs}$ & $1180 \mathrm{~g}$ & $\begin{array}{l}\text { 6/8/96 before dawn/ } \\
8 / 8 / 96 \text { 2115hrs } \\
11 / 8 / 96 \text { before dawn/ } \\
13 / 8 / 96 \text { 1930hrs }\end{array}$ & 3 \\
\hline $\begin{array}{l}\text { Kevin M/1 } \\
\text { Kevin M/2 }\end{array}$ & L13961 & $10 / 8 / 96$ & $2300 \mathrm{hrs}$ & $1350 \mathrm{~g}$ & $\begin{array}{l}\text { 6/8/96 before dawn/ } \\
6 / 8 / 96 \text { 2300hrs } \\
7 / 8 / 96 \text { before dawn/ } \\
\text { 10/8/96 2300hrs }\end{array}$ & 4 \\
\hline $\begin{array}{l}\text { Toni F/1 } \\
\text { Toni F/2 }\end{array}$ & L31706 & $16 / 8 / 96$ & 1800hrs & $1150 \mathrm{~g}$ & $\begin{array}{l}\text { 6/8/96 before dawn/ } \\
13 / 8 / 96 \text { 0045hrs } \\
13 / 8 / 96 \text { before dawn/ } \\
16 / 8 / 96 \text { 0130hrs }\end{array}$ & 3 \\
\hline $\begin{array}{l}\text { Ann F/1 } \\
\text { Ann F/2 }\end{array}$ & L14239 & $22 / 8 / 96$ & $2130 \mathrm{hrs}$ & $1300 \mathrm{~g}$ & $\begin{array}{l}13 / 8 / 96 \text { before dawn/ } \\
14 / 8 / 96 \text { before dawn } \\
16 / 8 / 96 \text { before dawn/ } \\
22 / 8 / 962130 \mathrm{hrs}\end{array}$ & $\begin{array}{l}1 \\
7\end{array}$ \\
\hline $\begin{array}{l}\text { Andrew } \mathrm{M} / 1 \\
\text { Andrew } \mathrm{M} / 2\end{array}$ & L14293 & $21 / 8 / 96$ & 0700hrs & $130.0 \mathrm{~g}$ & $\begin{array}{l}16 / 8 / 96 \text { before dawn/ } \\
16 / 8 / 962300 \mathrm{hrs} \\
18 / 8 / 96 \text { before dawn/ } \\
21 / 8 / 96 \text { before dawn }\end{array}$ & 1 \\
\hline $\begin{array}{l}\text { Danyon M/1 } \\
\text { Danyon M/2 }\end{array}$ & L19575 & $25 / 8 / 96$ & $1900 \mathrm{hrs}$ & $1150 \mathrm{~g}$ & $\begin{array}{l}\text { 18/8/96 1930hrs/ } \\
22 / 8 / 96 \text { 2300hrs } \\
23 / 8 / 96 \text { before dawn/ } \\
25 / 8 / 961900 \mathrm{hrs}\end{array}$ & 4 \\
\hline $\begin{array}{l}\operatorname{Dot} F / 1 \\
\operatorname{Dot} F / 2\end{array}$ & L22269 & $23 / 8 / 96$ & 1915hrs & $1150 \mathrm{~g}$ & $\begin{array}{l}24 / 8 / 96 \text { before dawn/ } \\
26 / 8 / 96 \text { 2000hrs } \\
27 / 8 / 96 \text { before dawn/ } \\
3 / 9 / 96 \text { 1930hrs }\end{array}$ & 3 \\
\hline Blythe M & L14010 & $\begin{array}{l}22 / 8 / 96 \\
29 / 8 / 96\end{array}$ & $\begin{array}{l}1630 \mathrm{hrs} \\
0145 \mathrm{hrs}\end{array}$ & $\begin{array}{l}1400 \mathrm{~g} \\
1400 \mathrm{~g}\end{array}$ & $\begin{array}{l}24 / 8 / 96 \text { before dawn/ } \\
29 / 8 / 96 \text { 0145hrs }\end{array}$ & 5 \\
\hline Ready Teddy M & L15731 & $\begin{array}{l}25 / 8 / 96 \\
1 / 9 / 96\end{array}$ & $\begin{array}{l}\text { 2015hrs } \\
\text { 2215hrs }\end{array}$ & $\begin{array}{l}1200 \mathrm{~g} \\
1250 \mathrm{~g}\end{array}$ & $\begin{array}{l}29 / 8 / 96 \text { before dawn/ } \\
1 / 9 / 96 \quad 2215 \mathrm{hrs}\end{array}$ & 4 \\
\hline
\end{tabular}


Three Microwave Telemetry Pico PTTs were deployed on Westland petrels in 1996. The low profile packages designed by us (Freeman et al in prep, see Appendix 1.) were constructed by Sirtrack Limited. The final weight of the packages was $37 \mathrm{~g}$ (approximately $3 \%$ of the birds' weight). The time interval between transmissions was 75 - 77 seconds; a compromise between location accuracy and battery life. The PTTs transmitted continuously and had a battery life of approximately 33 days (800 hours).

Tesa brand adhesive tape, as recommended by Wilson \& Wilson (1989) was used for attaching the PTTs to the bird's back feathers between the wings (Fig. 1). No birds had any significant feather loss or damage resulting from the PTT attachment or recovery. All PTTs were still firmly attached when recovered. Birds were weighed when the PTTs were attached and again when the PTTs were removed.

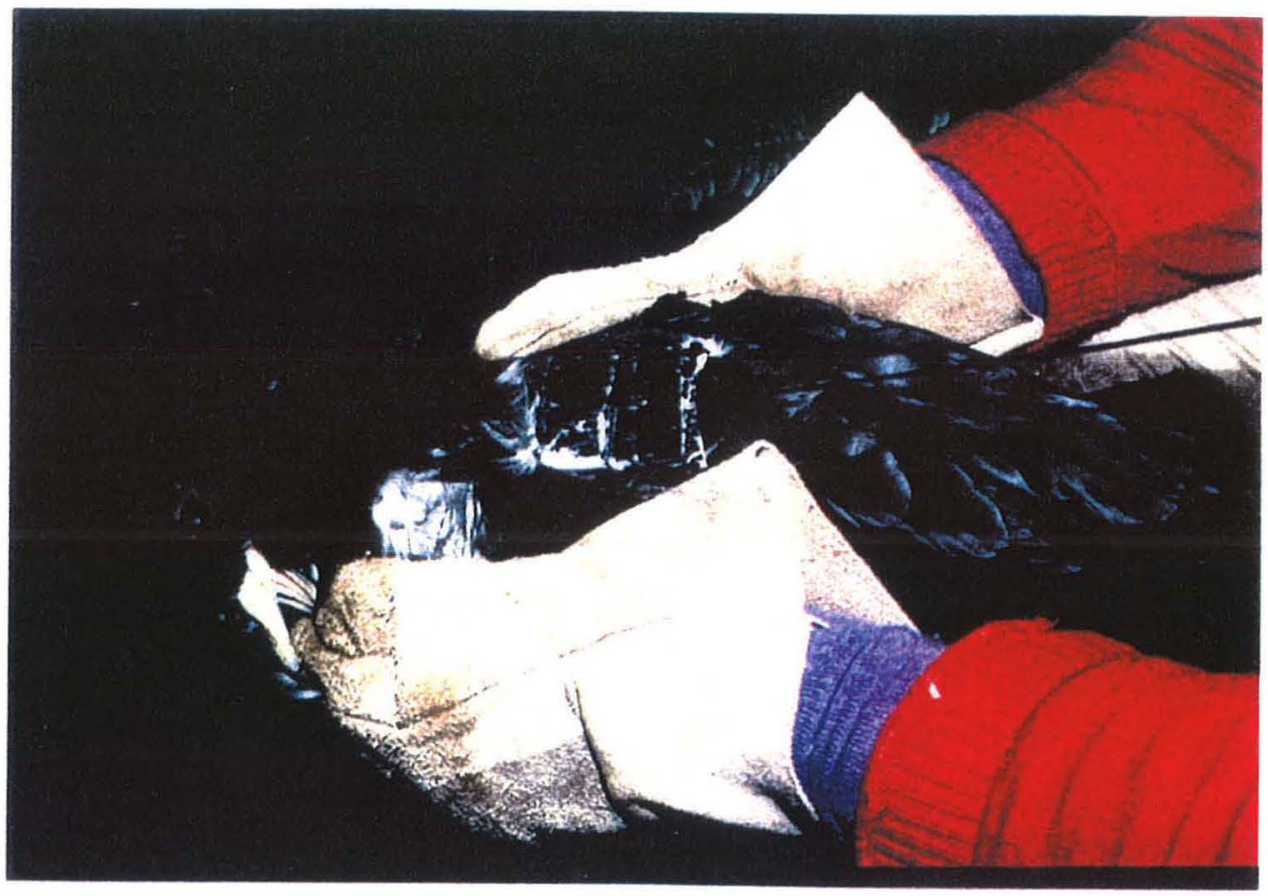

Figure 1. Satellite transmitter (PTT) being deployed on a Westland petrel, showing the Tesa tape attachment. 
In 1996, two alarm systems were installed to detect when satellite tracked birds returned to the colony. These proved invaluable in reducing damage to the ground cover from frequent burrow checking, and enabled us to shelter and rest while waiting.

One alarm was fitted to an AOR 1500 receiver by Sirtrack Limited. The unit detected any PTT signal emitted close to the colony. It was not clear at what distance this alarm could detect PTTs, but limited testing by us indicated that it was at least $1-2 \mathrm{~km}$ and probably more on the study site where signal interference was minimal. On detecting a PTT, a loud alarm would sound alerting us to the arrival of a bird. The advantage of this alarm was that it could monitor any number of PTTs. The disadvantage was that if a bird with a PTT was already on the colony the alarm would trigger continuously and could not therefore be set to detect the arrival of further birds.

The second alarm was designed and built by Lincoln University instrument technicians. This alarm was linked to an infra red sensor on a long cable. The sensor was installed at the burrow of a bird with a PTT when we wished to catch it, and when a bird entered the burrow, the alarm was triggered in the tent (Fig. 2).

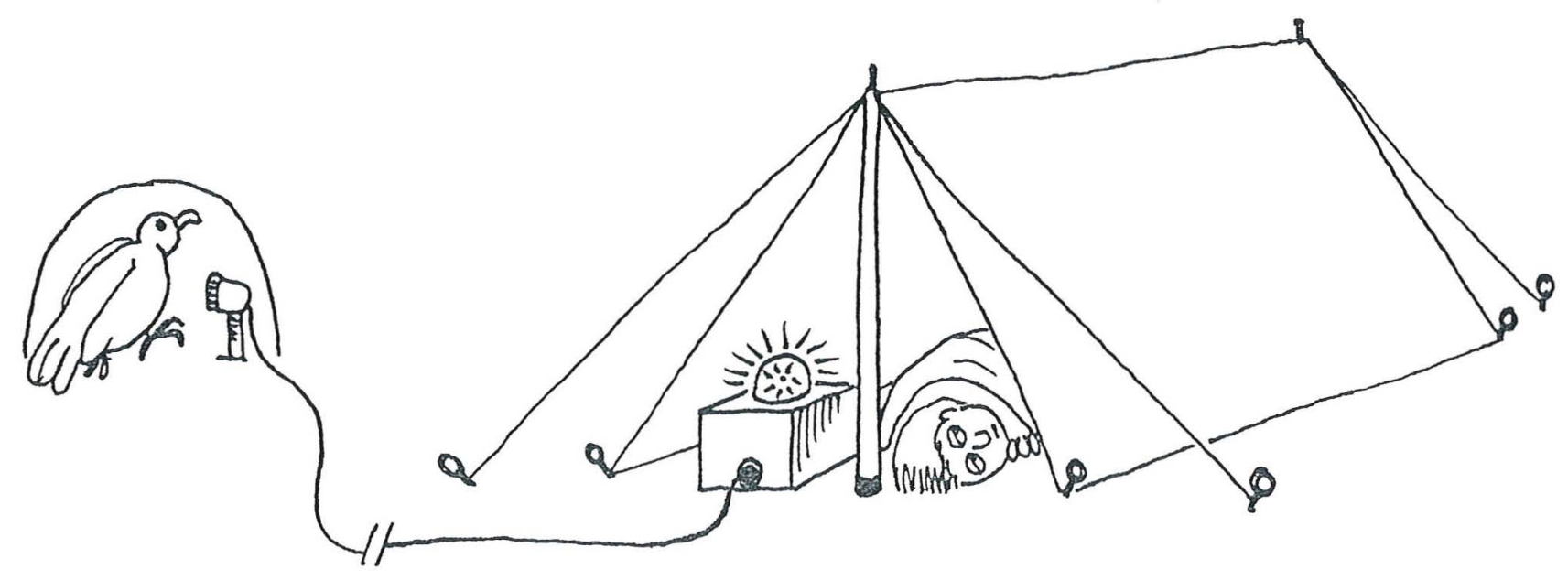

Figure 2. Infra red sensor installed at burrow entrance and set to trigger alarm (diagram C. Vink). 
The advantage of this alarm was that it could be operated regardless of other birds fitted with PTTs being in the area, and triggered only when a bird had actually returned to it's burrow. The disadvantage was that only one burrow could be monitored, and not only the tracked bird, but also its' partner and any other passing birds would trigger the alarm. By operating both of these alarms in tandem, the arrival of nearly all tracked birds was closely monitored.

Birds' locations were obtained from the Argos satellite tracking system which records location with seven classes of accuracy: Classes 1-3, less than $1 \mathrm{~km}$ error; Class 0 , above $1 \mathrm{~km}$ error; and Classes A, B and Z, accuracy not determined by Argos. Thirteen percent of the records we received were in Classes 1-3, 52\% in Class 0 and $35 \%$ in Classes $A, B$, and $Z$. We received an average of eight satellite fixes per day for each PTT. In 1995, a smoothing algorithm was fitted to the positions reported by Argos in an attempt to account for differences in the accuracy of points (Freeman et al in prep, see Appendix 1). The smoothed flights for 1995 are displayed here and used in analysis. However, as application of the smoothing algorithm made little difference to the mapped flights (Freeman et al in prep Figs. 3-5, see Appendix 1), and added another layer of interpretation to our results, it was not used in 1996. The raw data is presented for the 1996 flights apart from $Z$ class locations which were excluded from the analysis because of their obvious inaccuracy (eg distance between points implying impossible flight speeds and inland locations).

Positions of vessels in the WCSI (West Coast South Island) and Cook Strait fishing areas during the periods of satellite tracking were provided by NIWA ${ }^{1}$. The data provided is taken from vessels' TCEPR ${ }^{2}$ forms on which all vessels larger than $43 \mathrm{~m}$ are required to record the positions of their trawls.

The great majority of vessels in the West Coast hoki fishery are obliged to complete TCEPRs and it is estimated that $97 \%$ of the total catch in the WCSI fishing area is recorded on TCEPRs (S. Ballara pers. comm.). In the Cook Strait hoki fishery the situation is more complicated. Only vessels less than $43 \mathrm{~m}$ may

\footnotetext{
${ }^{1}$ National Institute of Water and Atmospheric Sciences

${ }^{2}$ Trawl and catch effort processing return
} 
fish in Cook Strait and these vessels are not obliged to complete TCEPRs although many do (c. $88 \%$ of total catch recorded on TCEPRs) (S. Ballara pers. comm.). The remainder complete CELR ${ }^{3}$ forms which are unlikely to have trawl positions recorded. The data for Cook Strait is therefore a less complete record of trawl positions.

For each day that Westland petrels were tracked, the position of all reported trawls from the TCEPRs were entered into the Geographical Information System ArcView ${ }^{\circledR}$ (Environmental Systems Research Institute Inc, 1994). The positions of birds were also entered into ArcView ${ }^{\circledR}$ and routes of the birds' foraging trips mapped. Distances between the birds' positions and the nearest hoki fishing vessel(s) were measured in ArcView®.

Petrels typically fly over vast areas of ocean without alighting except when food is sighted (Warham 1996). We might therefore find clues to a bird's activity, for example, whether it is searching for food or feeding, by examining the speeds at which birds travel during satellite tracked foraging trips. For example Walker et al. (1995) found differences in apparent flight speeds of wandering albatross Diomedea exulans at different stages of their foraging trips depending on whether they were commuting or foraging; a pattern similar to that observed for lightmantled sooty albatross Phoebetria palpebrata (Weimerskirch \& Robertson 1994).

If Westland petrels were actively scavenging around fishing vessels, we might expect to find that their average flight speeds would be lower in the hoki fishing areas than outside, because they would be spending more time on the water. To calculate the flight speeds of birds when they were in the vicinity of fishing vessels and when they were at some distance from the hoki fishing fleet, we measured the distance between pairs of satellite locations in $\operatorname{ArcView}{ }^{\circledR}$, and categorised them as either "close to" or "distant from" vessels.

We were concerned that the additional weight of the PTTs could alter the duration of the birds' foraging trips; perhaps lengthening them as the birds had to work

${ }^{3}$ Catch effort landing return 
harder travelling to food sources, or were less adept at catching prey. Therefore, the lengths of foraging trips of satellite tracked birds were compared with trips made by birds not carrying PTTs. The foraging trips of non-tracked birds were determined by direct observation of burrows, and by using automatic cameras installed at burrow entrances.

In 1995 and 1996, three 'Trailmaster® (TM 1500) automatic camera and event recording systems were installed at a total of eight burrows (Fig. 3). As a bird entered a burrow where a Trailmaster $($ was installed, it broke an infra red beam which triggered a camera positioned nearby. Birds in these burrows were marked with white enamel paint to allow males and females to be told apart in the resulting photographs (Fig. 4).

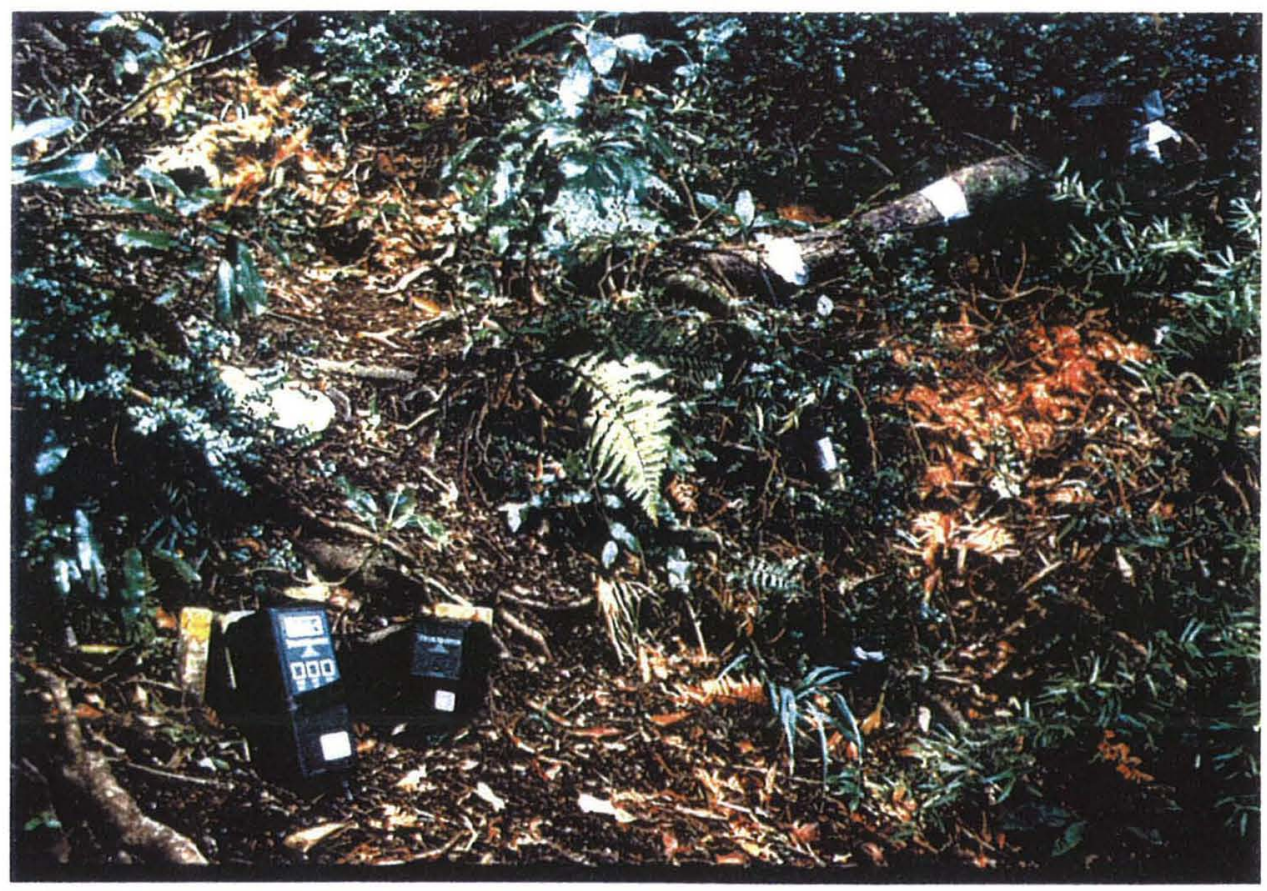

Figure 3. Trailmaster ${ }^{\circledR}$ camera (top right) and event recorder (bottom left) at a Westland petrel burrow. 


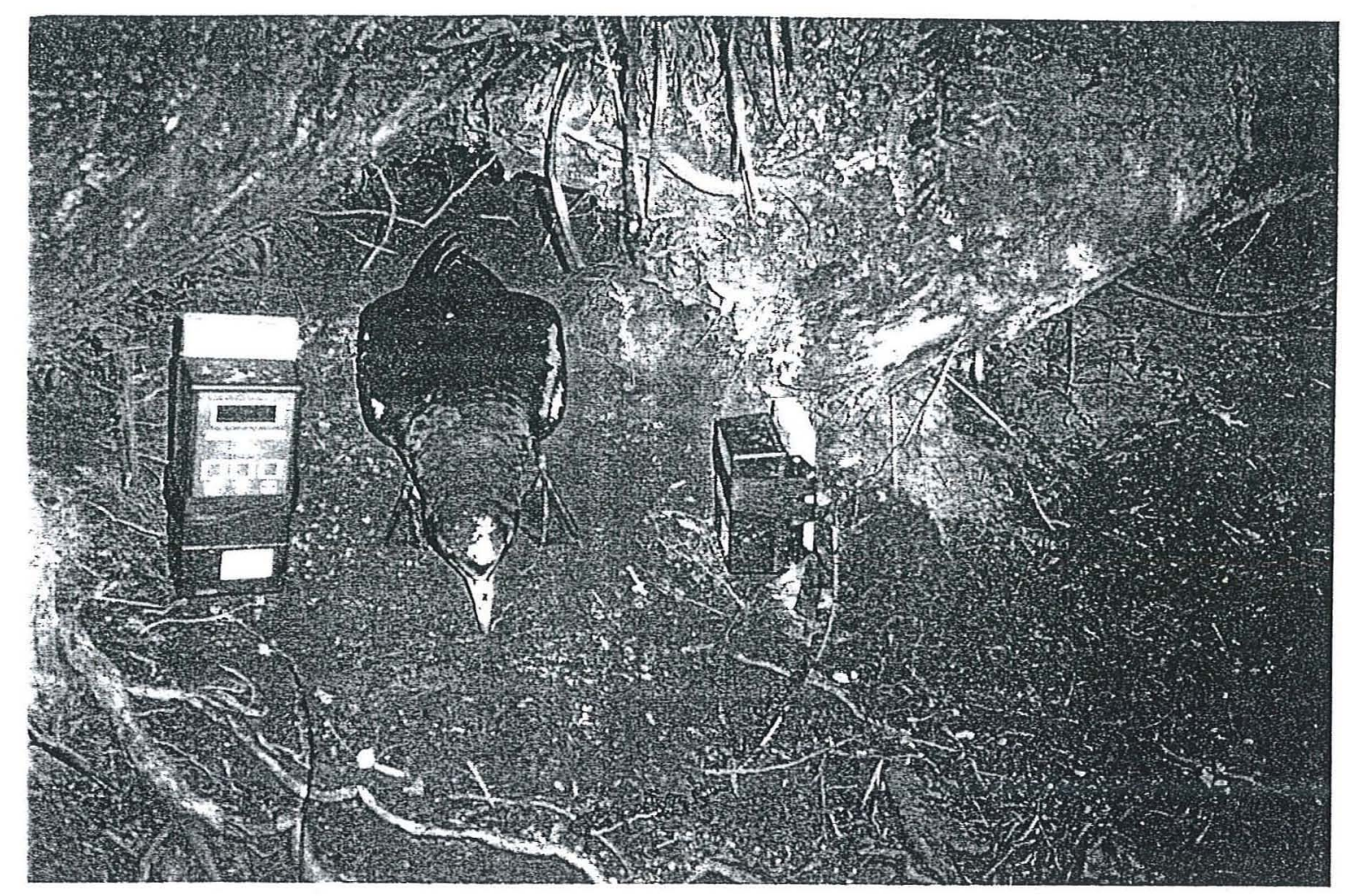

Figure 4. Photograph taken by Trailmaster( ${ }^{\circledR}$ camera of a male Westland petrel (marked on head and wings with white paint) leaving his burrow.

Recent studies that have examined satellite tracks in relation to the duration of foraging trips have found that foraging trip lengths reflect species' foraging strategies. For example, results obtained by Weimerskirch et al. 1993 on the movements of wandering albatross suggest that during short trips birds forage over the shelf areas and neighbouring waters, whereas on long trips, they forage over pelagic waters. This pattern seems to be widespread among petrels;

Weimerskirch et al. (1994a) found another four spècies which either alternated or mixed long and short foraging trips, storing energy to maintain adult condition during the long trips and delivering more food to their chick after short trips. The frequency distribution of their foraging trips was bimodal, with trips falling into distinct long and short categories. Significantly, two species in that study did not display this dual strategy. Black-browed albatrosses Diomedea melanophris and common diving petrels Pelecanoides urinatrix, both birds apparently restricted to the shelf during the breeding season, displayed a unimodal frequency distribution of foraging trip lengths unlike the bimodal pattern observed in the other, pelagic, species. We used satellite tracks to examine the relationship between proximity to fishing vessels and foraging trip length in Westland petrels and to address the 
potential contribution of fisheries waste to adult maintenance and chick provisioning.

To provide a control for the affects of handling, groups of control burrows with chicks, 11 in 1995 and 10 in 1996, were selected. Adults from these burrows were not satellite tracked, or used in the diet sampling and foraging trip studies which were also conducted.

Faced with increased energetic demands, adult petrels should maintain their own nutritional condition at the expense of their chick (Mauck \& Grubb 1995). We would therefore expect any detrimental effects of satellite tracking to be reflected in the condition of chicks. Just prior to fledging, in November 1995 and 1996, chicks of satellite tracked adults and chicks in control burrows had their wing lengths measured (flattened wing chord) and were weighed with a Pesola spring balance.

\subsection{RESULTS}

\subsection{Descriptions of the birds' flights}

The flights are illustrated in the accompanying maps (Figs. 5 - 12). Where low accuracy satellite fixes gave improbable inland positions for birds these are shown on the maps but are excluded from the flight paths. The 1995 maps are of the smoothed flights, and the 1996 maps do not include $Z$ class locations (see p7). Where a diet sample was collected from a bird returning from a tracked foraging trip, the contents of that sample are described. Samples were only collected from birds returning from their last tracked flight.

Paul

On Paul's first tracked flight (12/8/95 - 16/8/95), he spent time c. $60 \mathrm{~km}$ west of the colony and c. $100 \mathrm{~km}$ north west of the colony, mainly along the $200 \mathrm{~m}$ depth contour and in the vicinity of the WCSI hoki fishery. On his second tracked flight $(17 / 8 / 95-24 / 8 / 95)$ he travelled up to $300 \mathrm{~km}$ south west of the colony, again 
mainly following the $200 \mathrm{~m}$ depth contour, and spent less time near the WCSI fishing fleet (Fig. 5).

\section{Sandy}

Sandy remained relatively close to shore on his tracked flight (12/8/95 - 16/8/95); inside the $200 \mathrm{~m}$ depth contour and within $60-80 \mathrm{~km}$ west and south west of the colony. He spent little time in the vicinity of the WCSI hoki fishery; however the diet sample taken from Sandy on his return to the colony was comprised solely of fish, identified as hoki by electrophoresis (A.N.D. Freeman unpublished data) (Fig. $5)$.

\section{Spot}

On Spot's first tracked flight (18/8/95 - 31/8/95) he moved along the 200m depth contour, just west of the WCSI hoki fleet then flew directly to Cook Strait. He then travelled south to near Banks Peninsula where he was in the vicinity of fishing vessels. On his return to the colony he passed through the WCSI hoki fleet. Spot's second tracked flight $(1 / 9 / 95$ - 13/9/95) was 80 - 150km west of the colony and mainly beyond the WCSI hoki fleet. His third flight (14/9/95 - 19/9/95) consisted of a loop from north west to south west of the colony, out beyond the $200 \mathrm{~m}$ depth contour and west of the WCSI hoki fleet, c. 130km off shore (Fig. 6).

\section{Toni}

On Toni's first tracked flight (6/8/96 - 12/8/96) she travelled close to shore around Cape Farewell to Cook Strait but spent little time in the vicinity of the Cook Strait hoki fleet. She returned to the colony close to land and did not visit the WCSI fishing fleet. Toni's second flight (13/8/96 - 16/8/96) was also mostly close inshore. She kept within $20 \mathrm{~km}$ of the shore as she travelled up to $150 \mathrm{~km}$ north of the colony. On her return, she made a brief visit to the WCSI hoki fishing area $50-80 \mathrm{~km}$ west of the colony (Fig. 7). 


\section{Blythe}

Blythe's tracked flight (24/8/96 - 29/8/96) was along the 200m depth contour on the western edge of the WCSI hoki fishing area, $80 \mathrm{~km}$ west of the colony, and further south west $180 \mathrm{~km}$ from the colony (Fig. 7). The diet sample collected from Blythe on his return was comprised entirely of fish. It could not be matched with any common species found in fisheries waste.

\section{Merlene}

Merlene's first tracked flight (6/8/96 - 8/8/96) was mostly west of the WCSI hoki fishery and the $200 \mathrm{~m}$ depth contour, c. $150 \mathrm{~km}$ west of the colony. Her second flight (11/8/96 - 13/8/96) was mainly in the WCSI hoki fishing area, close to the $200 \mathrm{~m}$ depth contour, $80-100 \mathrm{~km}$ north west of the colony (Fig. 8). The diet sample collected from Toni after her second tracked flight was comprised entirely of heavily digested fish which could not be identified.

\section{Andrew}

On Andrew's first tracked flight which lasted just one day (16/8/96) he was c. $80 \mathrm{~km}$ west of the colony reaching as far offshore as the WCSI fishing fleet. His second flight (18/8/96 - 21/8/96) was mostly along the 200m depth contour amongst the WCSI hoki fishing fleet, c. $80 \mathrm{~km}$ west and north west of the colony (Fig. 9).

\section{Danyon}

On Danyon's first tracked flight (18/8/96 - 22/8/96) he was c.130-170km west of the colony, beyond the $200 \mathrm{~m}$ depth contour and the WCSI hoki fishing fleet. His second tracked flight $(23 / 8 / 96-25 / 8 / 96)$ was also beyond the WCSI fleet and $200 \mathrm{~m}$ contour, c. $80-100 \mathrm{~km}$ west of the colony (Fig. 10).

\section{Kevin}

Kevin's first tracked flight of one day $(6 / 8 / 96)$ was spent mostly in the vicinity of the WCSI hoki fishing fleet, $80-90 \mathrm{~km}$ west of the colony. On his second flight $(7 / 8 / 96-10 / 8 / 96)$ he moved in and out of the WCSI hoki fishing area, with most time spent 80 - 90km south west of the colony (Fig. 10). 
Ann

Ann's first tracked flight (13/8/96 - 14/8/96) took her $80 \mathrm{~km}$ west of the colony, out to the WCSI hoki fishing area and back. Her second flight (16/8/96 - 22/8/96) was mostly along the western edge of the WCSI hoki fishing fleet, beyond the $200 \mathrm{~m}$ depth contour, c. $90-200 \mathrm{~km}$ west of the colony (Fig. 11). The diet sample collected from Ann after her second tracked flight was comprised of $90 \%$ squid and $10 \%$ fish.

\section{Dot}

On her first tracked flight (24/8/96 - 26/8/96), Dot travelled beyond the WCSI hoki fishing fleet and $200 \mathrm{~m}$ contour, to $80-140 \mathrm{~km}$ west of the colony. Her second tracked flight (27/8/96-3/9/96) was mostly in the vicinity of hoki trawlers, around the $200 \mathrm{~m}$ depth contour (Fig. 11). Dot's diet sample, collected after her second tracked flight contained only moderately digested fish which could not be identified.

\section{Ready Teddy}

Ready Teddy's flight (29/8/96 - 1/9/96) was mainly inshore, only 20 - 30kms from land. He spent some time c. $100 \mathrm{~km}$ north west of the colony on the edge of the WCSI hoki fishing fleet (Fig. 12). The diet sample collected after this trip was comprised entirely of heavily digested fish which could not be identified. 


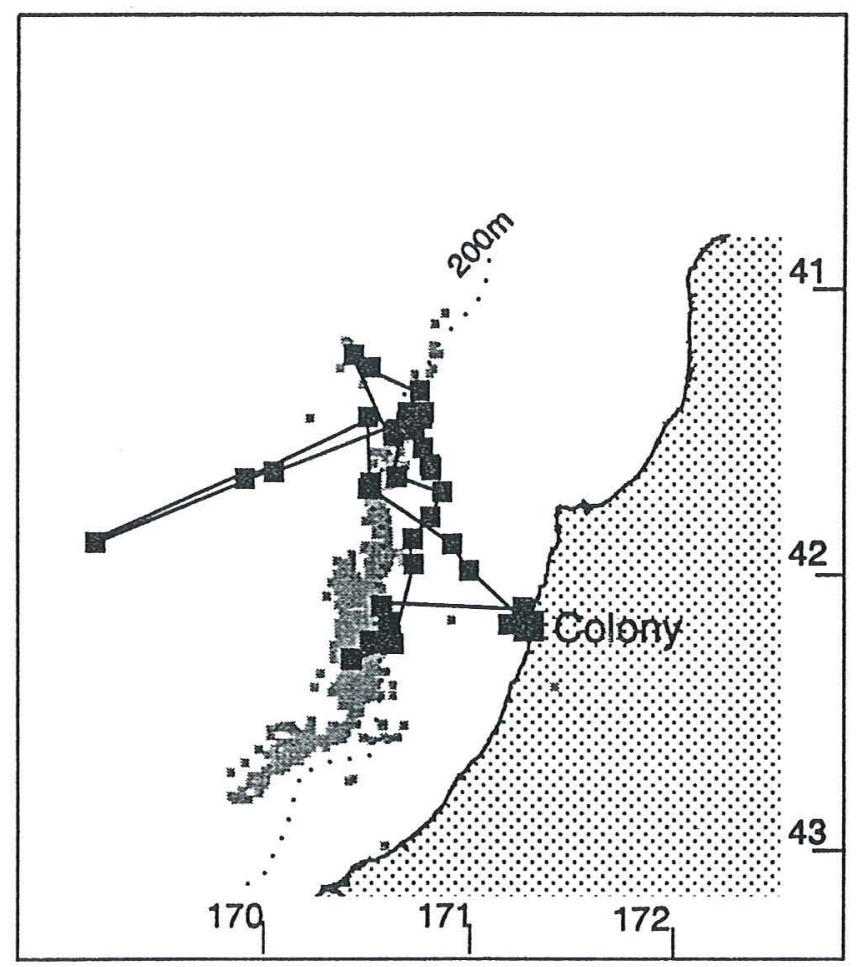

Paul Flight 1.

$12 / 8 / 95$ - 16/8/95

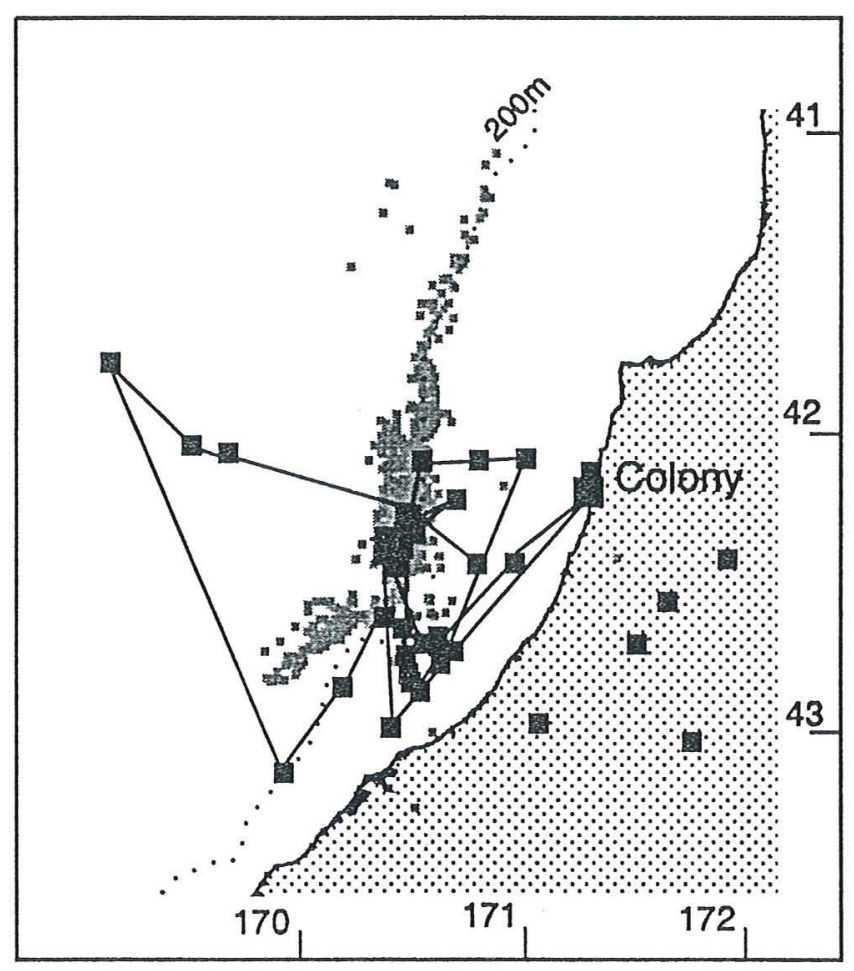

Sandy

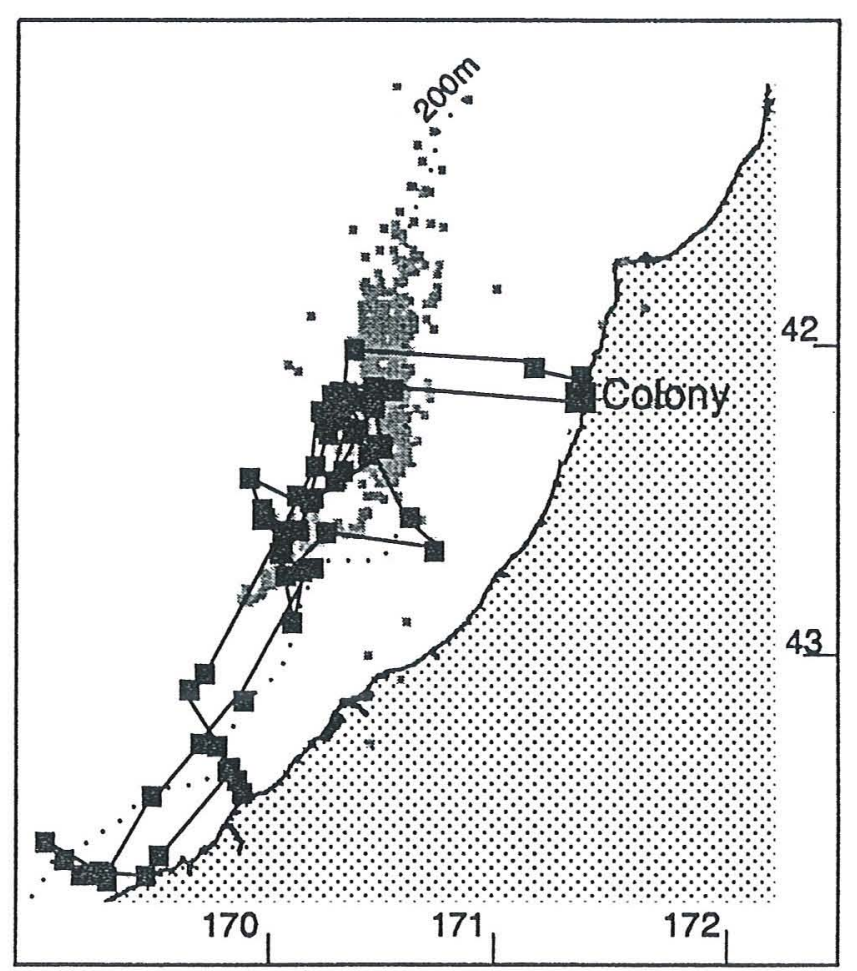

Paul Flight 2. $17 / 8 / 95$ - 24/8/95
Bird positions

Trawl locations during flight

Minimum

flight path

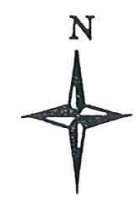

$\begin{array}{llllll}50 & 0 & 50 & 100 & 150 & \text { Kilometers }\end{array}$ $12 / 8 / 95-16 / 8 / 95$

Figure 5. Satellite tracks of Paul and Sandy. 


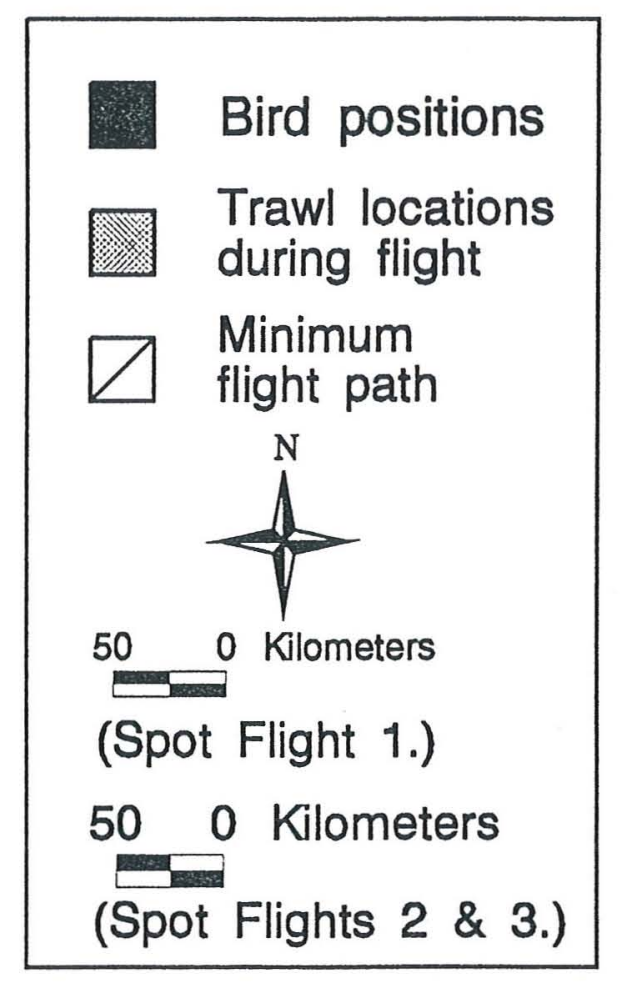

KEY

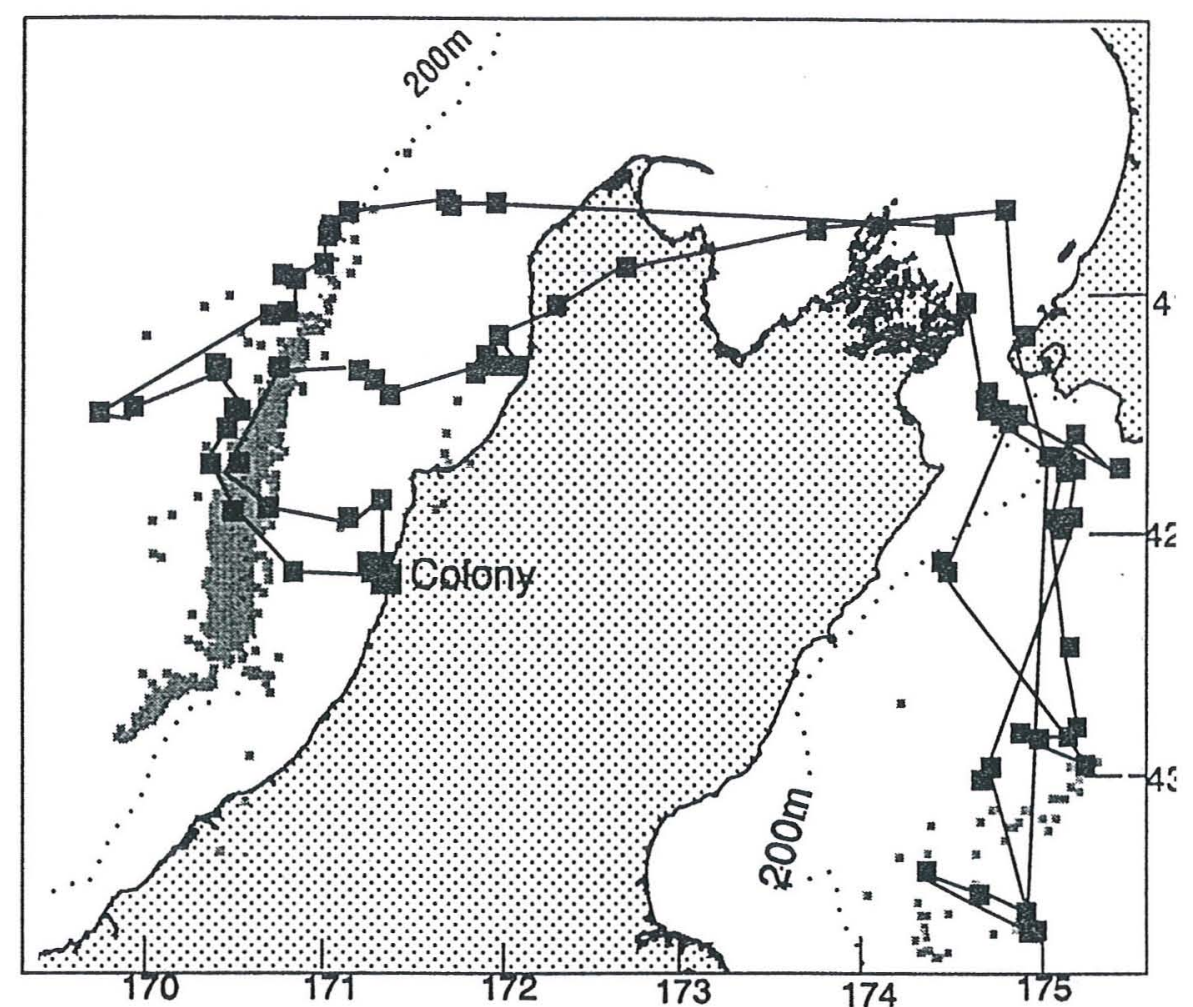

Spot Flight 1. 18/8/95 - 31/8/95

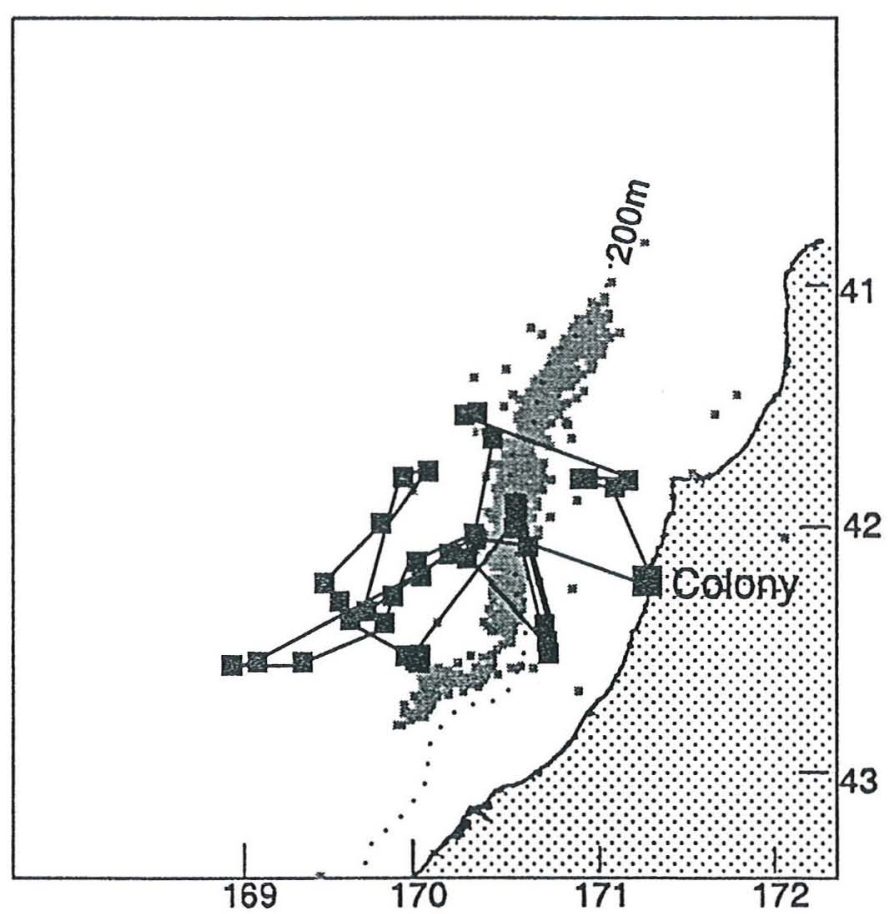

Spot Flight 2. 1/9/95 - 13/9/95

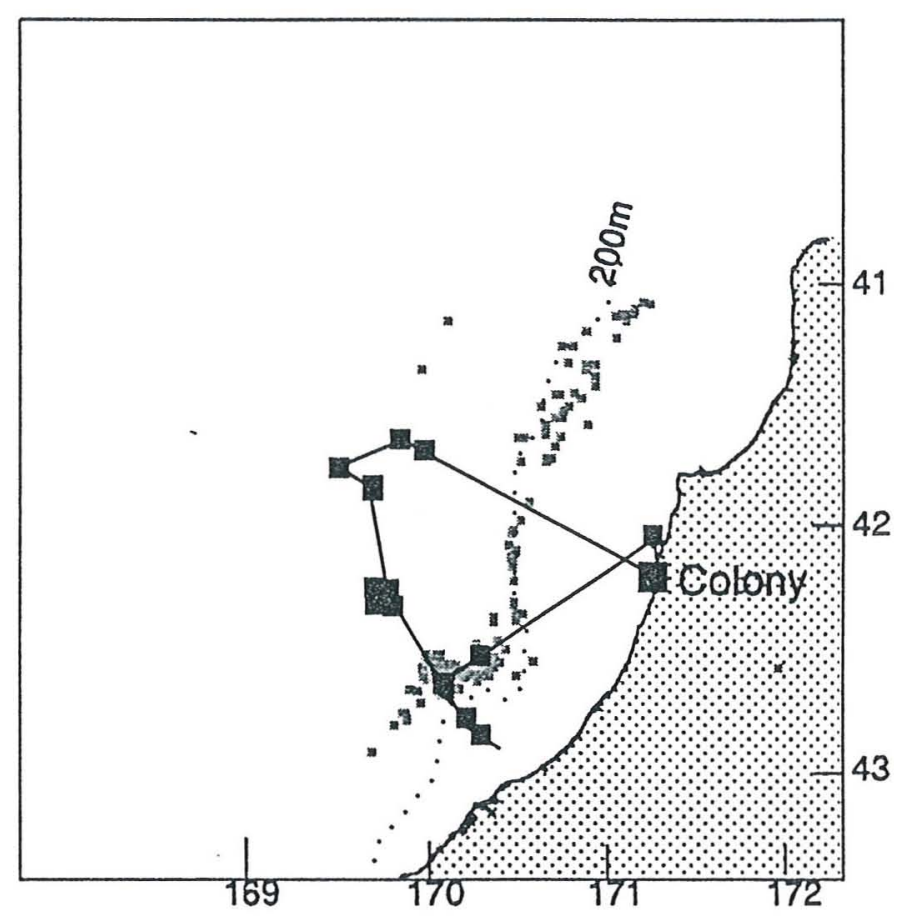

Spot Flight 3. 15/9/95 - 19/9/95

Figure 6. Satellite tracks of Spot. 

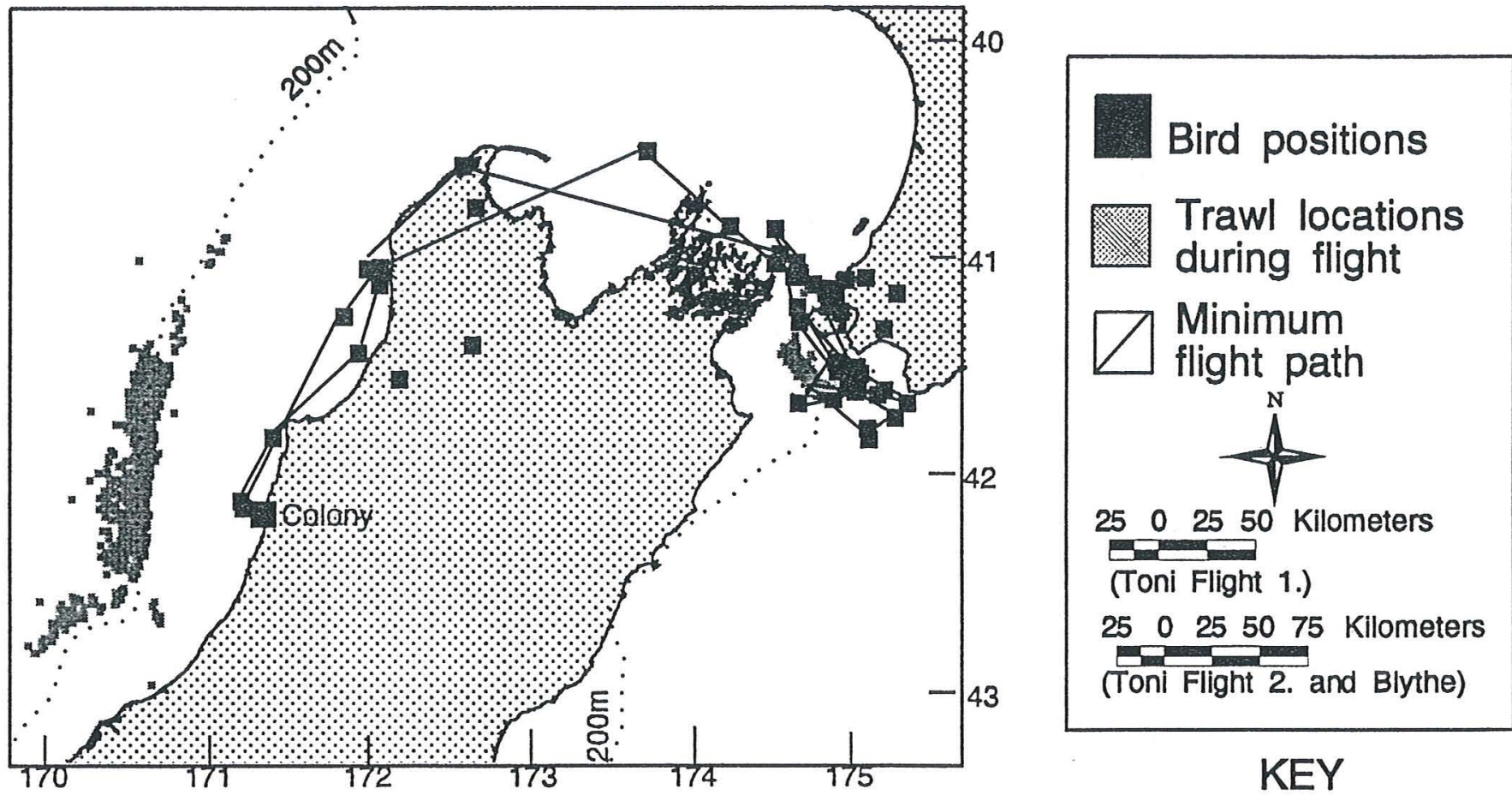

KEY

Toni Flight 1.

$6 / 8 / 96$ - 12/8/96

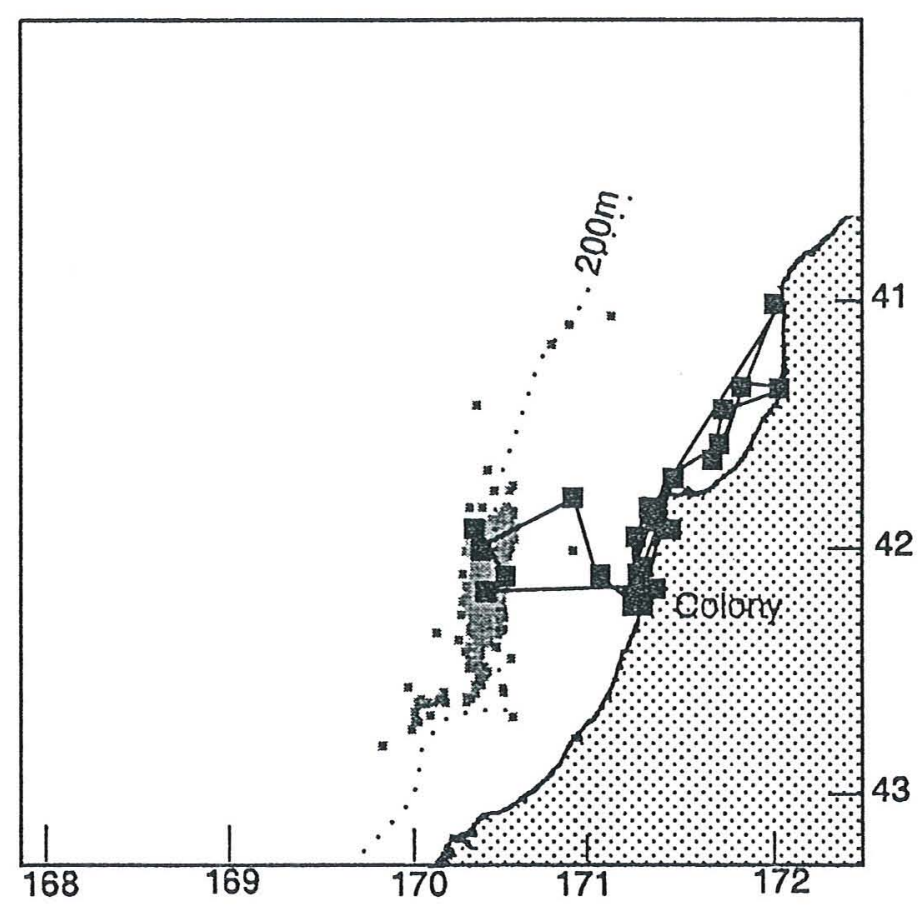

Toni Flight 2. $13 / 8 / 96$ - 16/8/96

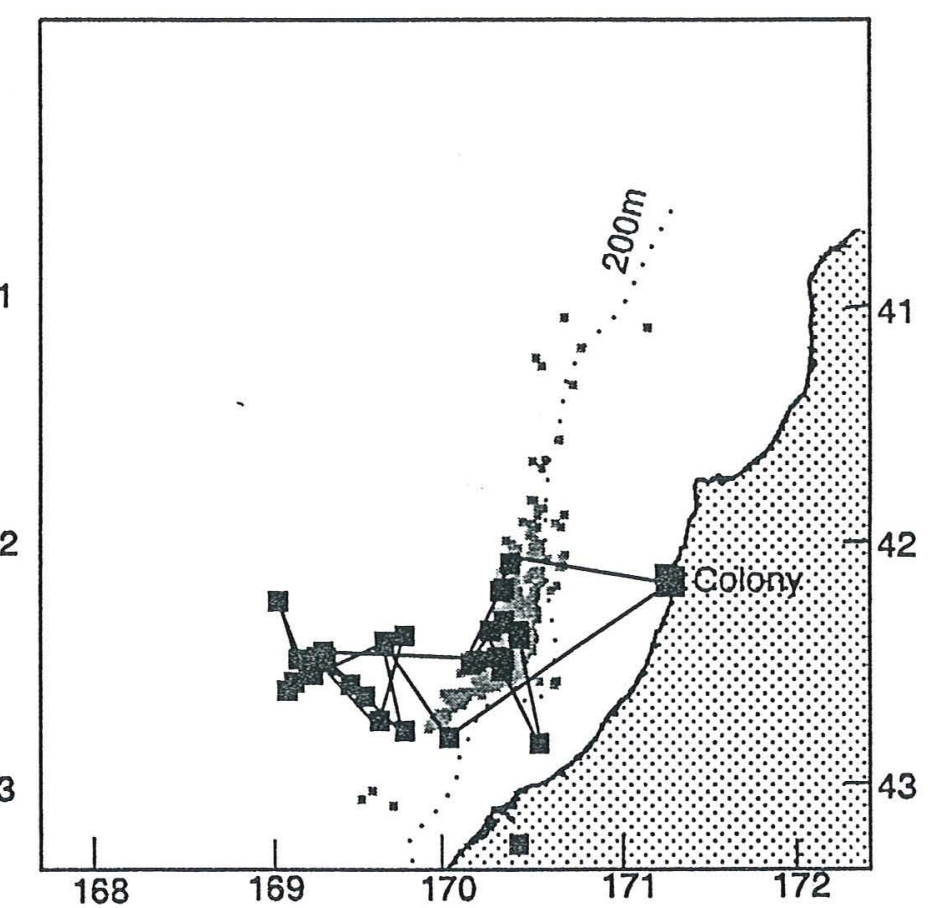

Blythe

Figure 7. Satellite tracks of Toni and Blythe. 


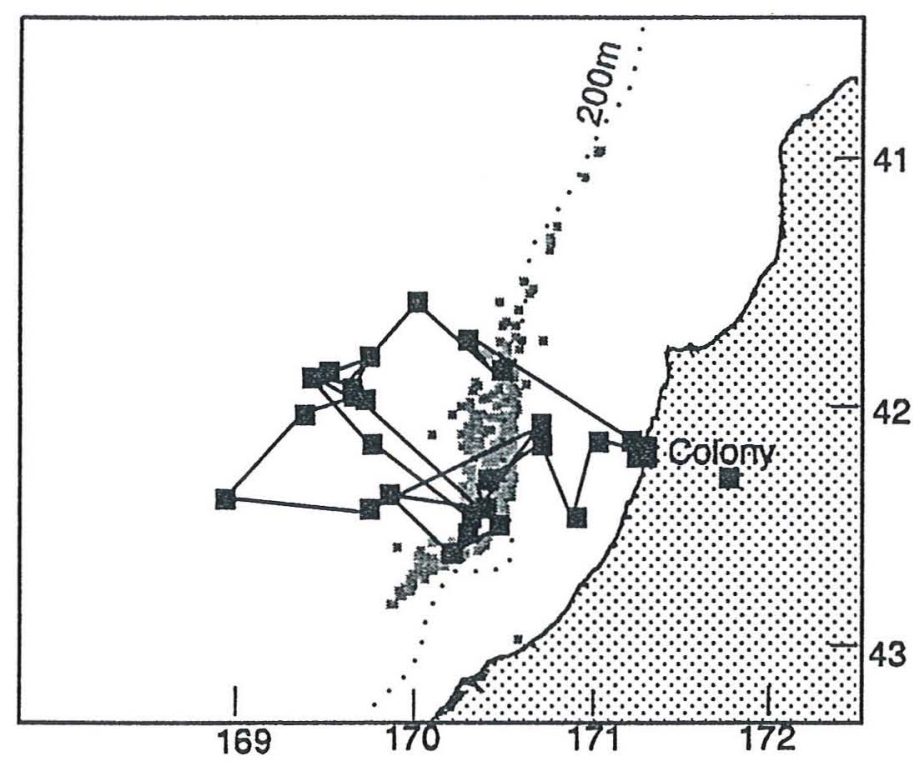

Merlene Flight 1.

6/8/96 - 8/8/96

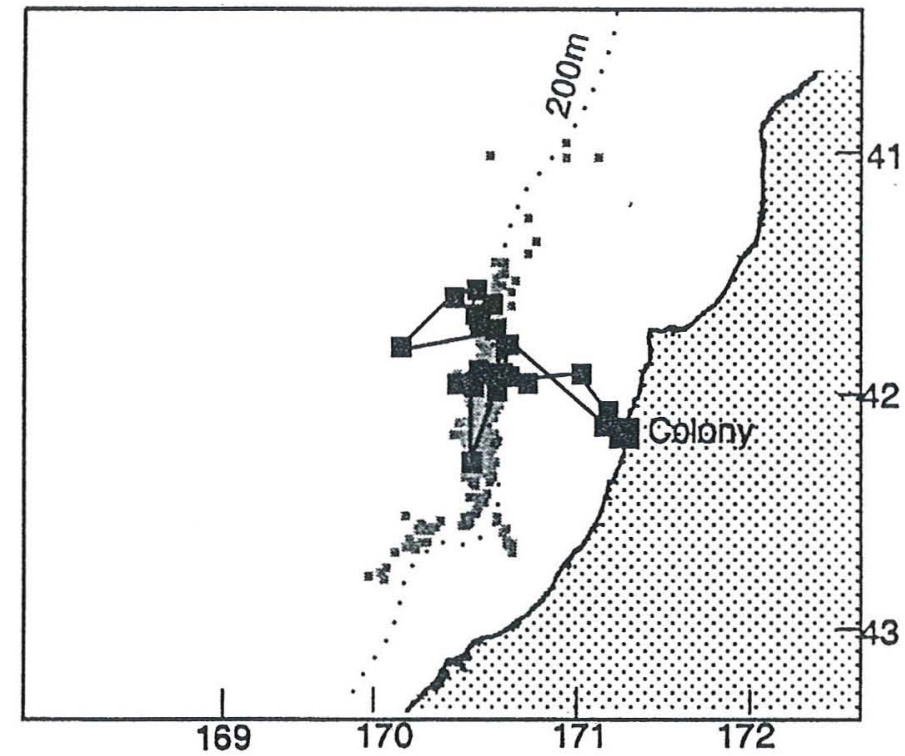

Merlene Flight 2. $11 / 8 / 96$ - 13/8/96

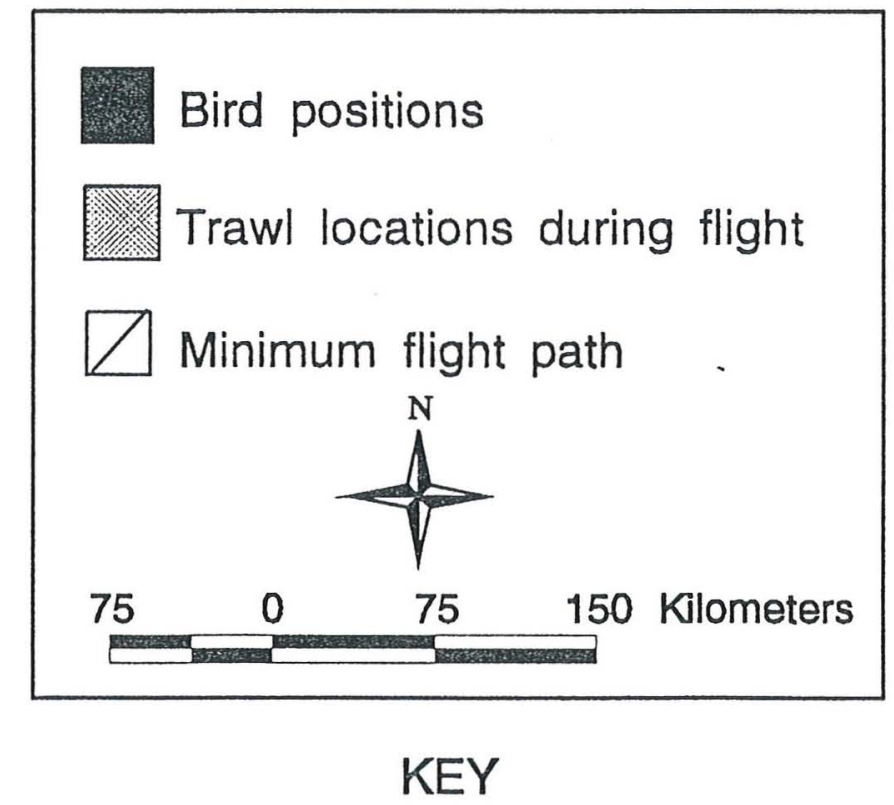

Figure 8. Satellite tracks of Merlene. 


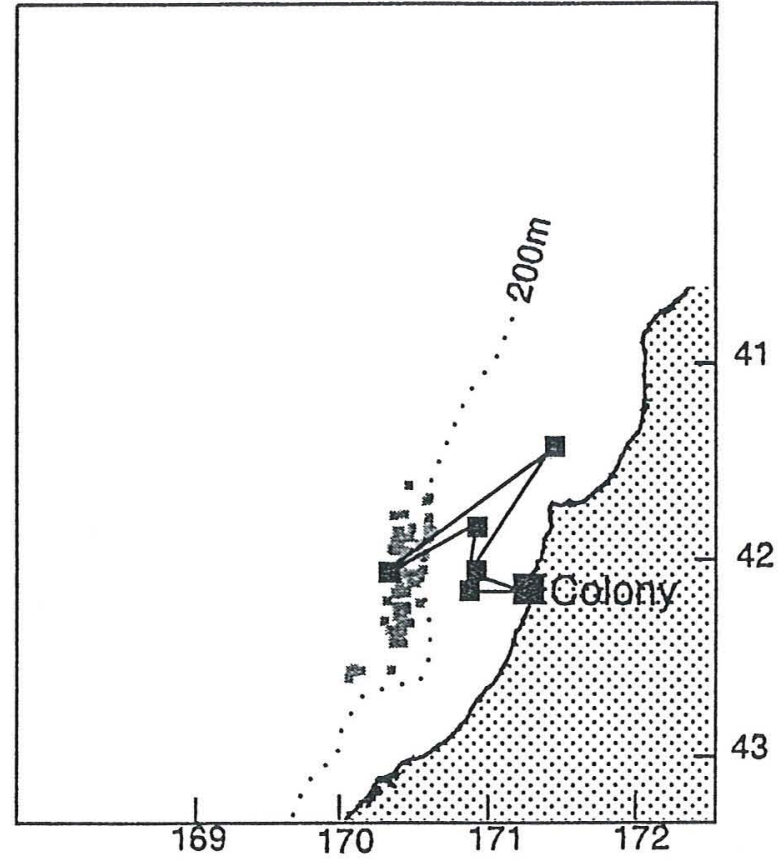

Andrew Flight 1. $16 / 8 / 96$

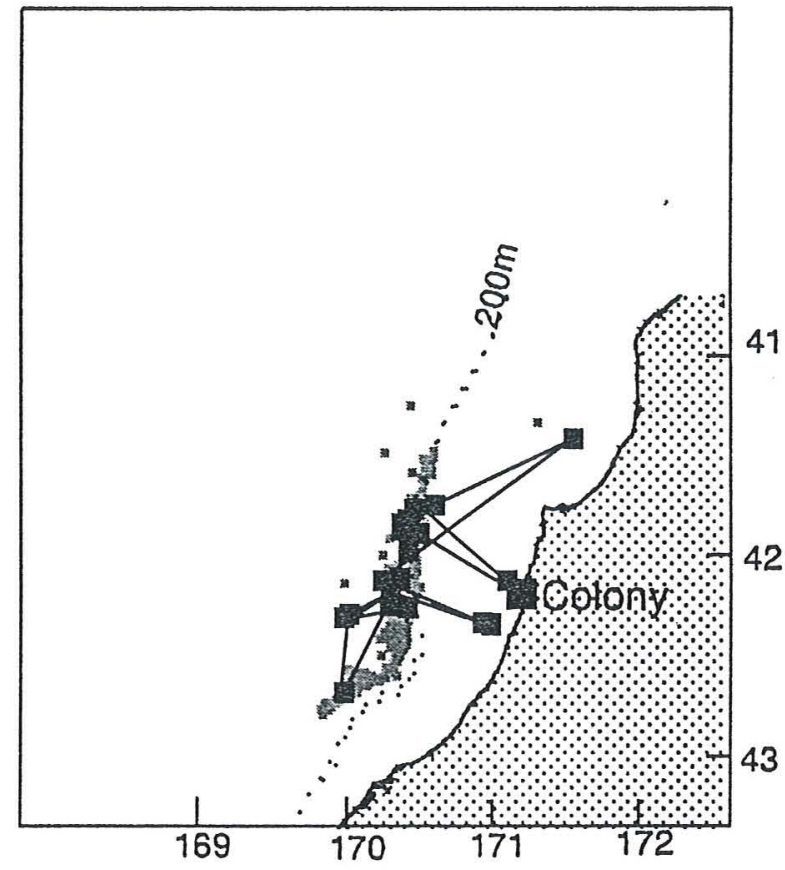

Andrew Flight 2. $18 / 8 / 96$ - 21/8/96

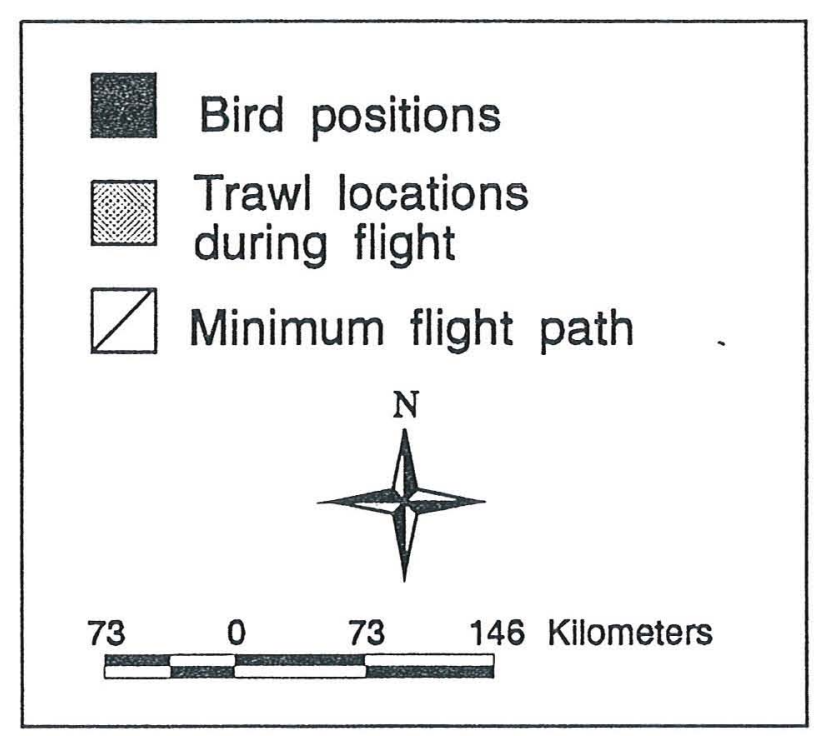

Figure 9. Satellite tracks of Andrew. 

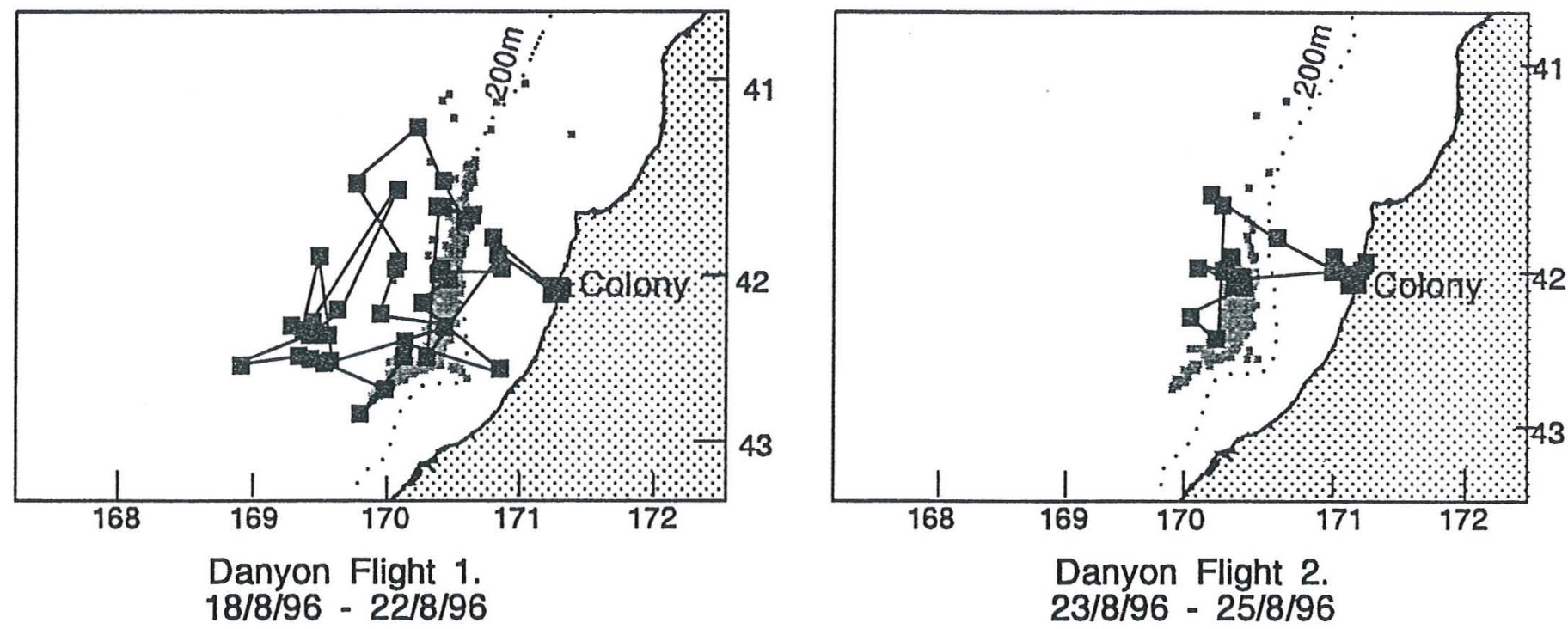

Danyon Flight 2. $23 / 8 / 96-25 / 8 / 96$
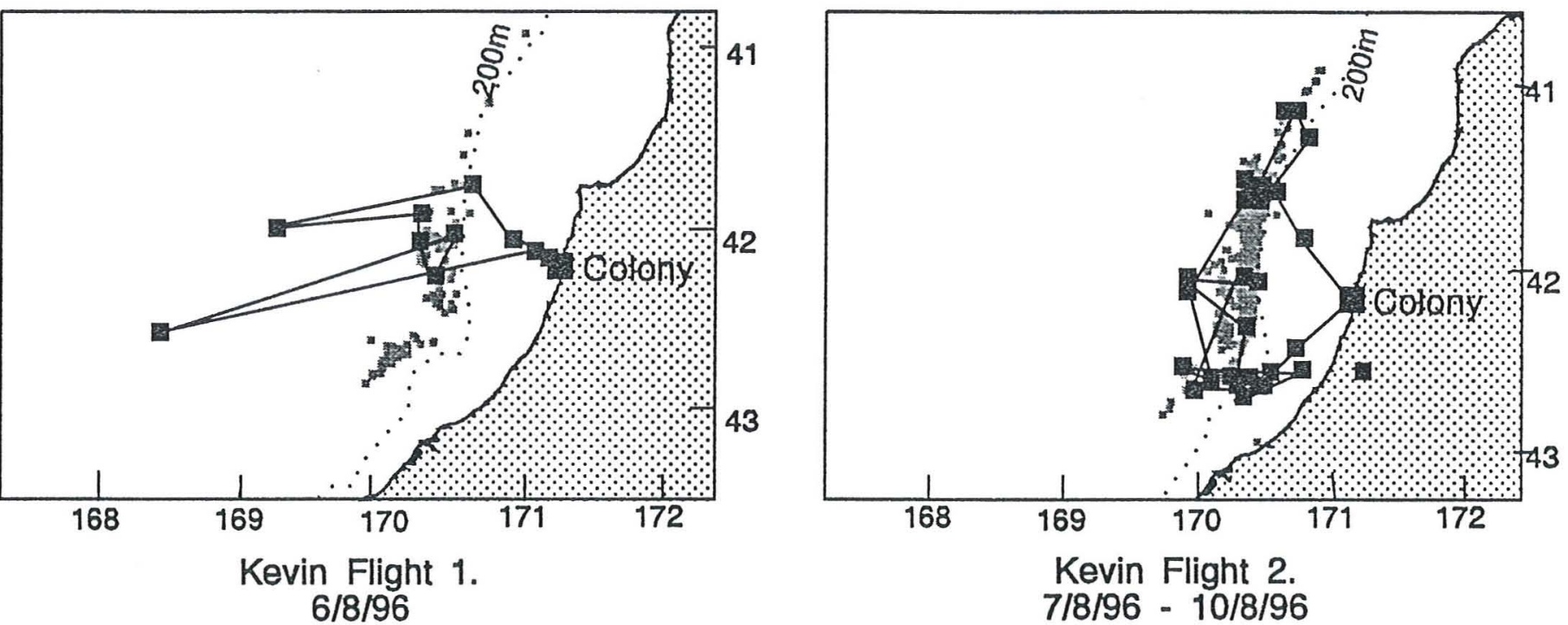

Kevin Flight 2.

$7 / 8 / 96-10 / 8 / 96$

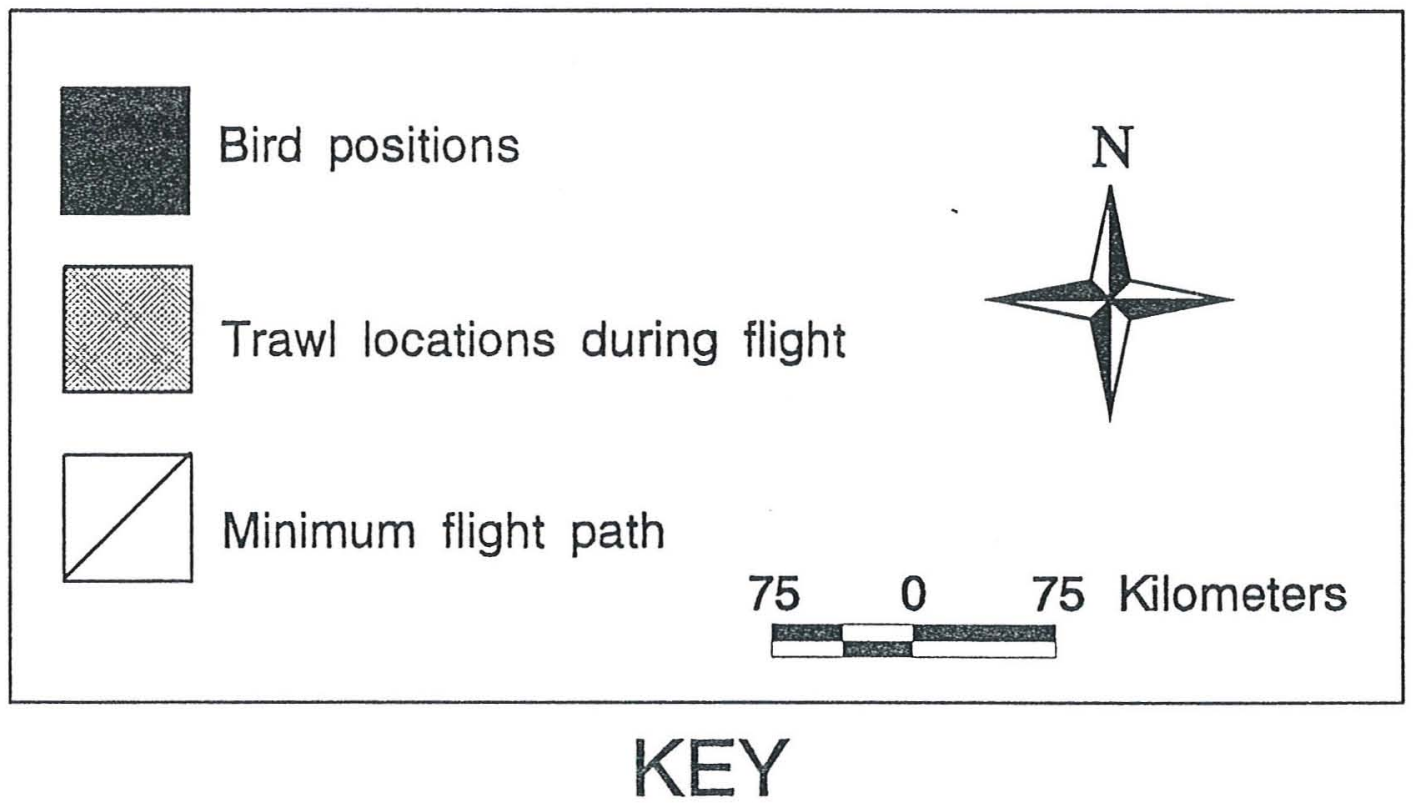

Figure 10. Satellite tracks of Danyon and Kevin. 


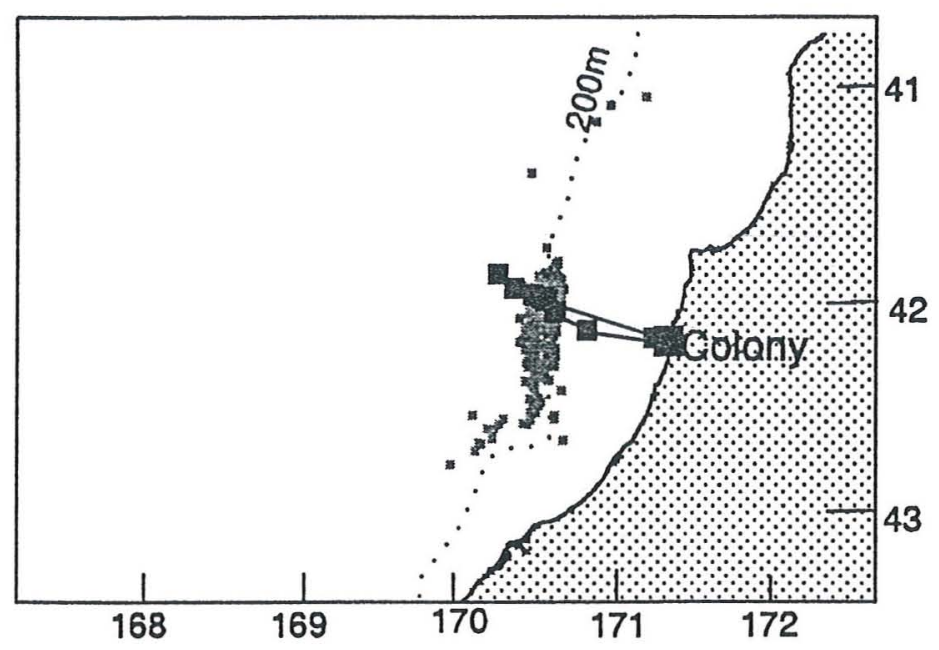

Ann Flight 1.

13/8/96 - 14/8/96

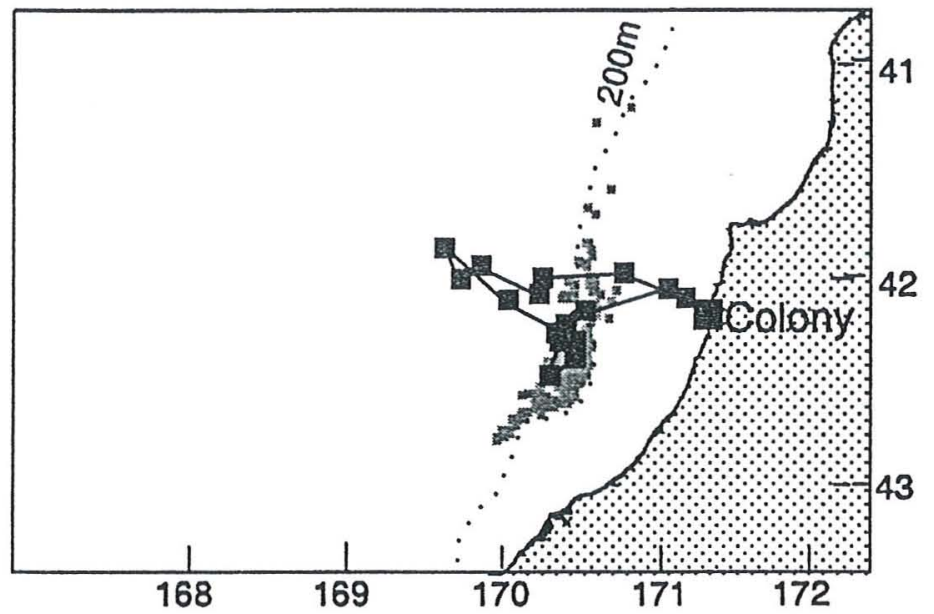

Dot Flight 1.

$24 / 8 / 96-26 / 8 / 96$

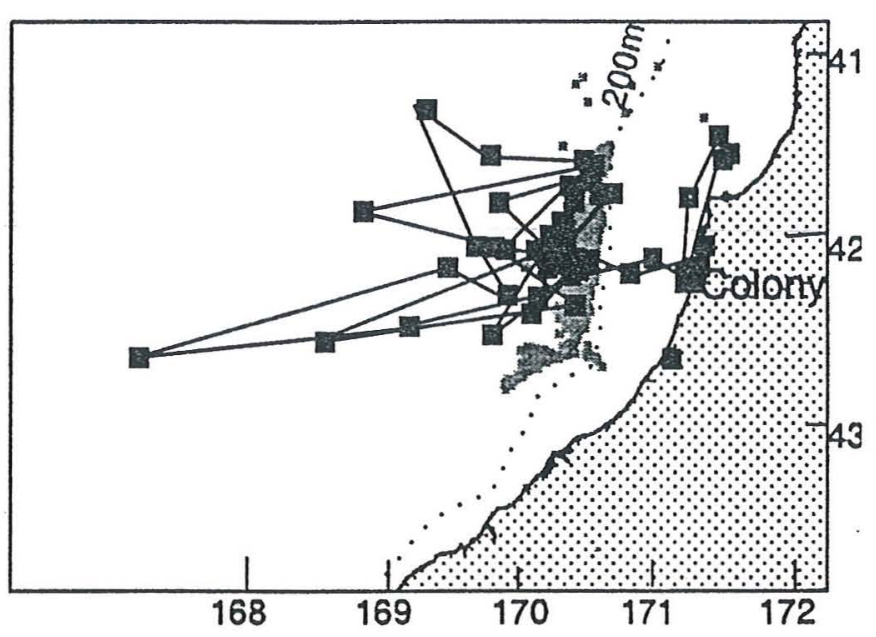

Ann Flight 2. $16 / 8 / 96-22 / 8 / 96$

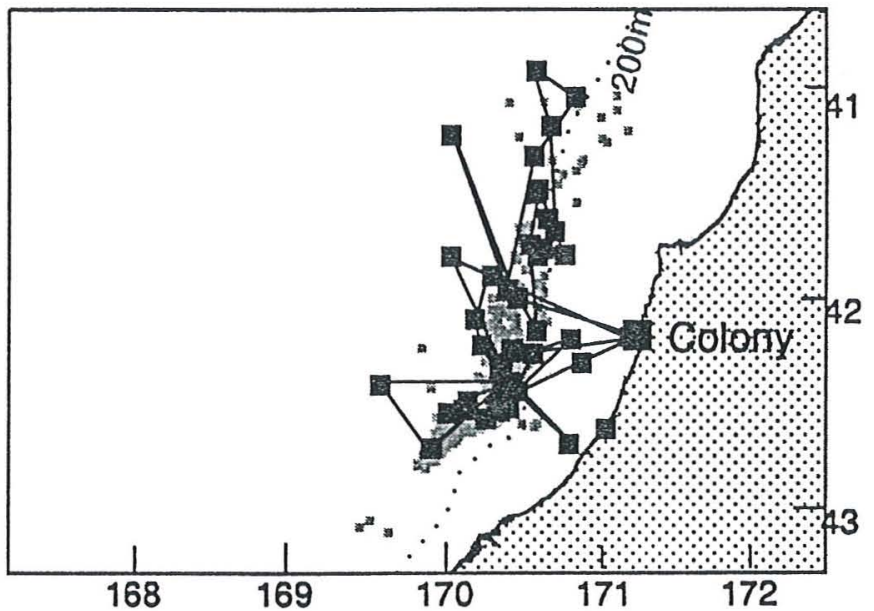

Dot Flight 2.

$27 / 8 / 96-3 / 9 / 96$

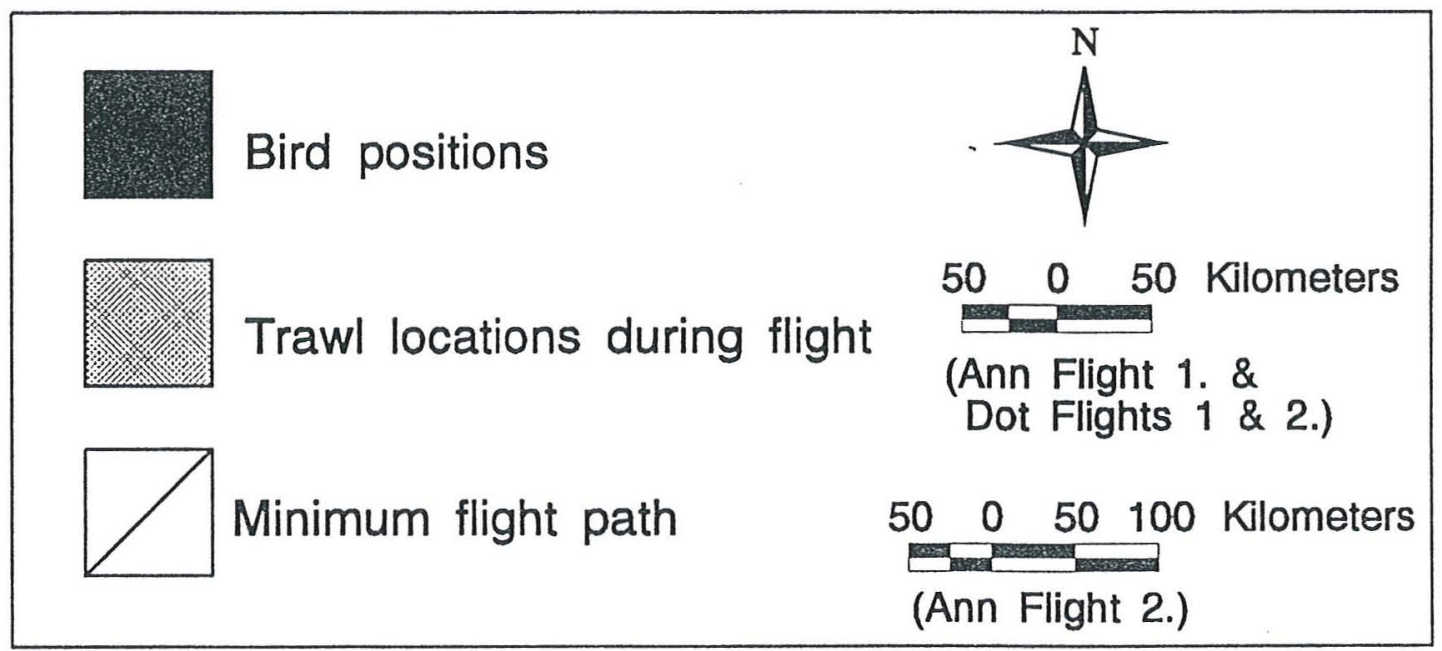

\section{KEY}

Figure 11. Satellite tracks of Ann and Dot. 

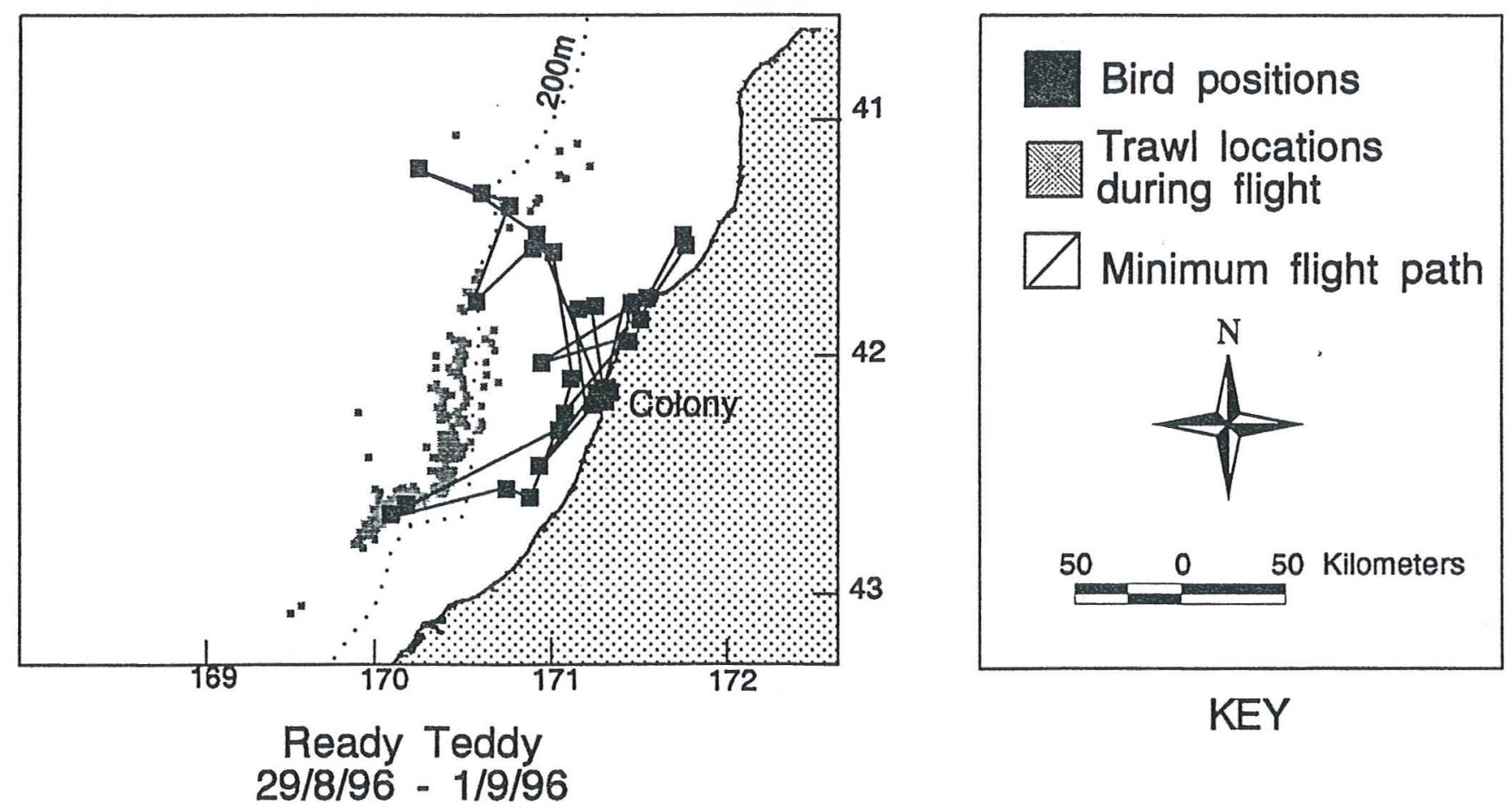

Figure 12. Satellite track of Ready Teddy. 


\subsection{Time spent in the vicinity of hoki fishing vessels}

For each day of tracking, the number of bird positions recorded "close to" fishing vessels ( $<5 \mathrm{~km}$ from one or more trawls occurring on that day) were compared to the number recorded "distant from" fishing vessels ( $>5 \mathrm{~km}$ from any trawl occurring on that day) (Table 2).

Table 2. Number of Westland petrel positions recorded "close to" and "distant from" trawls made by WCSI and Cook Strait hoki vessels.

\begin{tabular}{|c|c|c|c|c|}
\hline Bird & $\begin{array}{l}\text { No. close to } \\
\text { trawls }(<5 \mathrm{~km})\end{array}$ & $\%$ & $\begin{array}{c}\text { No. distant } \\
\text { from trawls }(>5 \mathrm{~km})\end{array}$ & $\%$ \\
\hline Andrew & 14 & 58 & 10 & 42 \\
\hline Kevin & 16 & 50 & 16 & 50 \\
\hline Dot & 21 & 49 & 22 & 51 \\
\hline Merlene & 20 & 47 & 23 & 53 \\
\hline Sandy & 16 & 39 & 25 & 61 \\
\hline Ann & 20 & 38 & 32 & 62 \\
\hline Paul & 32 & 31 & 71 & 69 \\
\hline Danyon & 15 & 29 & 36 & 71 \\
\hline Blythe & 9 & 28 & 23 & 72 \\
\hline Ready Teddy & 3 & 12 & 23 & 88 \\
\hline Toni & 7 & 11 & 54 & 89 \\
\hline Spot $^{1}$ & 4 & 6 & 58 & 94 \\
\hline
\end{tabular}

'Only Spot's first tracked flight is included, as his second and third trips extended beyond the end of the hoki fishing season.

The $5 \mathrm{~km}$ level was set in recognition of the flight speed of the birds, the movement of the vessels over each day, and the imprecision of measuring distances in ArcView ${ }^{\circledR}$. Positions recorded for birds as they left or returned to the colony, or were obviously travelling to feeding areas (eg Spot and Toni's routes to Cook Strait) were excluded from this analysis. Where birds completed more than one flight, the data from all flights is combined. The number of positions recorded in the "close" and "distant" categories are assumed to equate to the proportion of time birds spent in those areas. The birds' positions reported by Argos were regularly spaced throughout the day, apart from a gap in satellite coverage which 
generally occurred between mid morning and mid afternoon. It can not, of course, allow for the unknown movements of birds between satellite locations.

Although the average proportion of time that birds spent in the vicinity of the hoki fishing fleets was 33\%, this was highly variable. Some birds spent about half of their time in the vicinity of fishing vessels, whereas others spent as little as 6$12 \%$ of their time there. This was not related to sex, as high and low proportions were recorded for both males and females. We did not have enough information about the prior breeding success of the tracked birds to assess whether age or breeding experience could be a factor. The two birds which travelled to Cook Strait spent the least time in the vicinity of fishing vessels. Despite the Cook Strait hoki fishing fleet operating in the same general area, these birds did not associate with vessels.

The proportion of time spent in the vicinity of hoki vessels also varied between trips of the same individual. The most marked examples of this were Merlene, whose first tracked flight was mostly west of the WCSI hoki fleet and whose second flight was mainly in the fishing area, and Ann whose first flight was mainly in the fishing area but whose second tracked flight was west of the WCSI fishing fleet (Figs. 8, 11).

The ratio of positions recorded close to hoki fishing vessels was similar during both night and day, indicating that the proportion of time Westland petrels spent in the vicinity of hoki fishing vessels was not influenced by the time of day (Table $3)$. 
Table 3. No. of Westland petrel positions recorded during the day and night, "close to" and "distant from" trawls by WCSI and Cook Strait hoki vessels.

\begin{tabular}{l|cccc}
\hline & $\begin{array}{c}\text { No. close to } \\
\text { trawls }(<5 \mathrm{~km})\end{array}$ & $\%$ & $\begin{array}{c}\text { No. distant } \\
\text { from trawls }(>5 \mathrm{~km})\end{array}$ & $\%$ \\
\hline Day & 83 & 32 & 178 & 68 \\
Night & 94 & 30 & 215 & 70 \\
\hline \multicolumn{5}{r}{ Day =0600hrs - 1800hrs. Night $=$ 1800hrs - 0600hrs. }
\end{tabular}

\subsection{Apparent flight speeds in the vicinity of hoki fishing vessels}

Although the average flight speed varied greatly between individual birds, mean flight speeds were significantly lower when in the vicinity of hoki fishing vessels (paired sample $\mathrm{t}$-test; $\mathrm{t}=-3.65, \mathrm{P}=0.005)$ (Table 4 ).

Table 4. Average flying speeds of Westland petrels when "close to" and "distant from" trawls by WCSI and Cook Strait hoki vessels.

\begin{tabular}{l|cc}
\hline \multicolumn{1}{c|}{ Bird } & $\begin{array}{c}\text { Speed close to } \\
\text { trawls }(<5 \mathrm{~km})(\mathrm{km} / \mathrm{h})\end{array}$ & $\begin{array}{c}\text { Speed distant from } \\
\text { trawls }(>5 \mathrm{~km})(\mathrm{km} / \mathrm{h})\end{array}$ \\
\hline Andrew & 4 & 8 \\
Kevin & 6 & 14 \\
Dot & 11 & 16 \\
Merlene & 8 & 21 \\
Sandy & 11 & 17 \\
Ann & 17 & 23 \\
Paul & 4 & 9 \\
Danyon & 5 & 21 \\
Blythe & 10 & 15 \\
Toni & 8 & 10 \\
Spot & 15 & 11 \\
\hline
\end{tabular}

NB. Due to the small number of records, it was not possible to calculate a flight speed close to vessels for Ready Teddy. He is therefore not included in this part of the analysis.

Flight speeds also varied between flights of the same individual. Again, the most marked examples were Merlene and Ann whose average speeds were much 
slower when on foraging trips in the vicinity of hoki fishing vessels. On their flights outside the WCSI fishing area, Merlene and Ann averaged $23 \mathrm{~km} / \mathrm{h}$ and 25 $\mathrm{km} / \mathrm{h}$ respectively; on their flights mostly within the fleet area they averaged $9 \mathrm{~km} / \mathrm{h}$ and $3 \mathrm{~km} / \mathrm{h}$ respectively.

\subsection{Foraging trip length}

Foraging trips of tracked birds ranged from one to 13 days (Table 1; Table 2 in Appendix 1). Although the three trips of one day's duration were all within the WCSI hoki fishing fleet area, medium length and long foraging trips varied greatly; some mainly in the hoki fishing area, some mainly out of the fishing area, and some that moved in and out of the area occupied by the hoki fishing fleet.

The frequency distribution of foraging trip lengths was unimodal.

\subsection{Time spent near fishing vessels before return to the colony}

A feature of most of the tracked flights was the time spent in the vicinity of fishing vessels at the end of a foraging trip. In 15 out of the 22 tracked flights (68\%), satellite location data indicated that birds had stopped in the area occupied by the fishing fleet during the twelve hours before their return to the colony. The criteria used were; either recorded as $<5 \mathrm{~km}$ from vessels for two or more consecutive satellite fixes or within $5 \mathrm{~km}$ of vessels at the time of a high quality satellite fix (Class 1-3) ${ }^{4}$.

\footnotetext{
${ }^{4}$ High quality satellite fixes are more likely to be from stationary birds.
} 


\subsection{Comparison of adult weights and controls}

\subsubsection{Weight of tracked birds}

In 1995 all three birds tracked increased in weight between PTT attachment and recovery (Table 2 in Appendix 1). In 1996, six birds increased in weight, two remained the same weight, and only one lost weight, indicating that, in general, they fed successfully during their foraging trips (Table 1 p4).

\subsubsection{Chick weight, wing length and fledging success}

Chicks whose parent(s) were satellite tracked were compared with control groups of chicks whose parents were not handled during the season, apart from establishing egg-laying and chick-hatching (Table 5).

Table 5. Comparison of study and control burrow chicks.

\begin{tabular}{l|cccc}
\hline & $\begin{array}{c}1995 \\
\text { Fledging } \\
\text { success }\end{array}$ & $\begin{array}{c}\text { Mean weight(g)/ } \\
\text { wing length }(\mathrm{mm}) \\
15 / 11 / 1995\end{array}$ & $\begin{array}{c}1996 \\
\text { Fledging } \\
\text { success }\end{array}$ & $\begin{array}{c}\text { Mean weight(g)/ } \\
\text { wing length }(\mathrm{mm}) \\
11 / 11 / 1996\end{array}$ \\
\hline \multirow{3}{*}{$\begin{array}{l}\text { Study } \\
\text { Control }\end{array}$} & $100 \%(\mathrm{n}=3)$ & $1542 / 315(\mathrm{n}=3)$ & $100 \%(\mathrm{n}=7)$ & $1758 / 316(\mathrm{n}=6)^{*}$ \\
& $64 \%(\mathrm{n}=11)$ & $1486 / 329(\mathrm{n}=7)$ & $100 \%(\mathrm{n}=10)$ & $1930 / 325(\mathrm{n}=10)$ \\
\hline significance & \multicolumn{5}{c}{$\mathrm{ns}(\mathrm{P}=0.65 / 0.68)$} & $\mathrm{ns}(\mathrm{P}=0.17 / 0.49)$ \\
\hline
\end{tabular}

* One study burrow chick had already fledged by $11 / 11 / 96$.

The three chicks of birds satellite tracked in 1995 all fledged, as did the seven chicks of birds tracked in 1996. In neither year was there any significant difference between the weights and wing lengths of chicks of satellite tracked birds and a set of control burrow chicks, although small sample sizes in both years question the reliability of these comparisons. 


\subsubsection{Foraging trip length}

The duration of the 20 flights undertaken in August 1995 and 1996 by the satellite tracked birds was compared with the duration of trips undertaken by birds who were not carrying PTTs. A total of 74 such trips, recorded over August 1995 and 1996 were used in the analysis. These trips included some by birds which had been tracked previously. Spot's second and third trips are excluded from the analysis due to the lack of measured trips for untracked birds in September.

Birds spent significantly more time at sea when they were carrying a PTT; spending on average 4.45 days at sea compared to non-tracked birds which spent a mean of only 1.76 days at sea ( $t$ test; $t=-6.6, P=0.00$ ). Whereas $93 \%$ of foraging trips of birds not carrying PTTs were of three days or less, only $45 \%$ of satellite tracked trips were of three days or less. Fifty percent of foraging trips by satellite tracked birds were of four to eight days duration (Fig. 13).

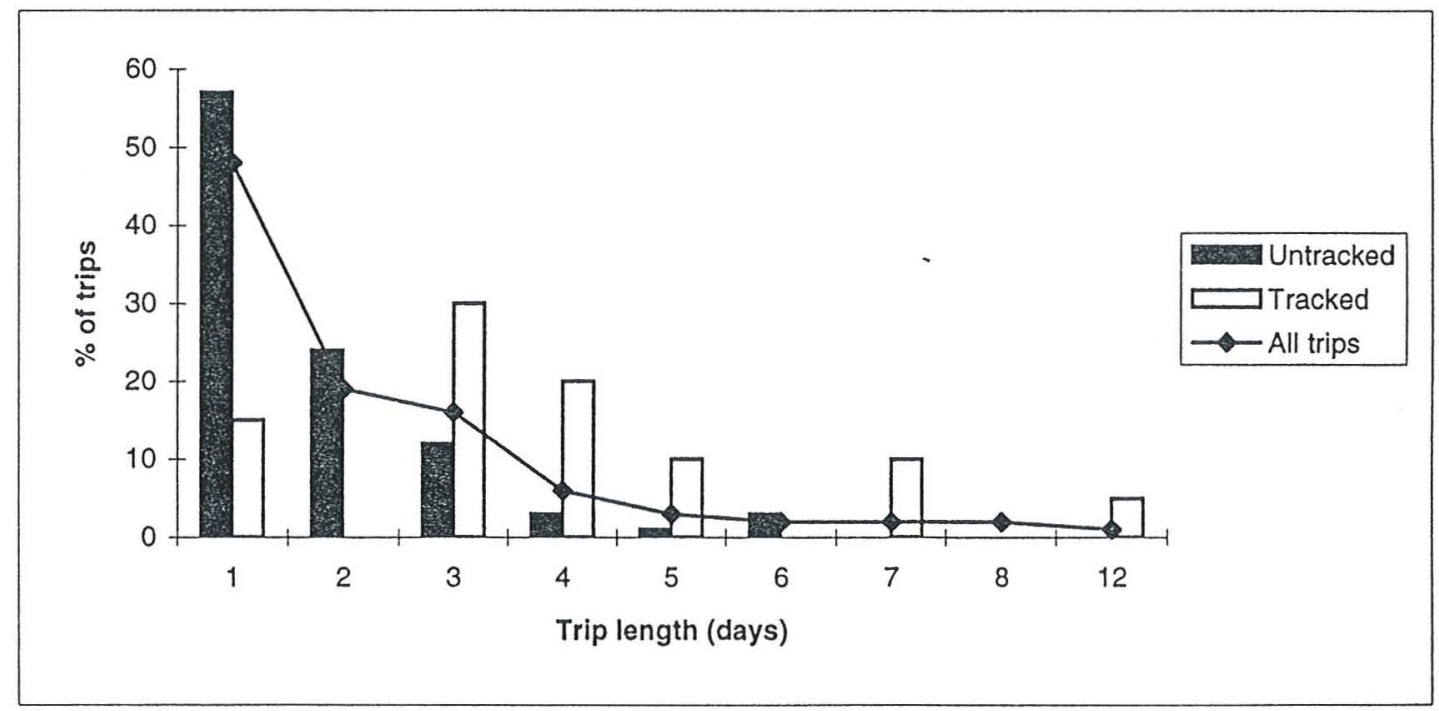

Figure 13. The frequency distributions of foraging trip lengths of tracked and untracked Westland petrels, August 1995 and 1996. 


\subsection{DISCUSSION}

Satellite tracking showed that some Westland petrels spent as much as half of their total foraging time in the vicinity of hoki fishing vessels and nine out of the 12 birds tracked spent at least $25 \%$ of their time there. These birds spent ample time in areas where fisheries waste could make an important contribution to their diet. Some Westland petrels, however, spent very little time associating with vessels and this suggests that the importance of fisheries waste may vary among individuals.

The above figures are an upper limit on the amount of time birds could be spending actually scavenging at vessels, as the methodology was not precise enough to determine when birds were exactly coincident with vessels in space and time. Fisheries data could not be more specific than trawls occurring on a given day, and the majority of positions received from Argos for birds in this study were of unknown accuracy. Over the relatively short distances that Westland petrels fly, location errors are likely to be significant and limit our ability to relate positions to fishing activity with precision.

The major problem in interpreting the implications of the amont of time spent around fishing vessels is that time spent is not necessarily proportional to food consumed. Waste from the hoki fishery is readily available and it may not take long for birds to consume large volumes. Although recorders have been developed which allowed researchers to detect times of ingestion in Wandering albatross (Weimerskirch et al. 1994b), Westland petrels were too small for such devices and so, in the meantime, these problems are intractable.

We cannot be certain of the extent to which the co-occurrence of fishing vessels and Westland petrels is coincidental. Hoki spawning occurs in winter when they school in large aggregations (Langley 1993). The WCSI and Cook Strait hoki fisheries are concentrated on these spawning aggregations which largely coincide with the $200 \mathrm{~m}$ depth contour. The upper part of the continental slope between 200 and about $800 \mathrm{~m}$ is a diverse and rich marine habitat. Upwelling of deep, nutrient- 
rich water often occurs along the upper edge of the continental slope, especially on the West Coast, leading to a high productivity of plankton and fishes (Ayling \& Cox, 1982). This zone is the source of much of the Westland petrel's natural prey (A.N.D. Freeman unpublished data) and presumably during their breeding season Westland petrels would forage extensively there regardless of the fishery.

It is not possible to separate out the effects of the hoki fishery and the shelf break on the distribution of Westland petrels at sea. However, we know from diet studies (A.N.D. Freeman unpublished data) that the relationship between Westland petrels and fishing vessels is not merely coincidental as fisheries waste forms a significant part of their diet. The slower average flight speeds recorded for birds in the vicinity of fishing vessels is further evidence of extensive scavenging.

Walker et al. (1995) point out that calculated speeds and distances are affected by the interval between satellite locations. Frequent satellite locations closely map a bird's flight, whereas infrequent locations underestimate distance and speed because they miss many small changes in direction. With an average of only eight locations per day, our estimates of flight speed are likely to be seriously underestimated. However, it is the relative flight speeds close to and away from vessels that are of most interest in this study, rather than the actual flying speeds attained.

We did not observe any difference in behaviour by night and day in the Westland petrels which were tracked by satellite either in their average flight speeds or the proportion of time spent in the vicinity of fishing vessels. This suggests that Westland petrels scavenge around fishing vessels equally by day and by night. Whereas most natural prey is only available at night, due to the diurnal vertical migration of prey to and from the surface layers (Imber 1976), waste from the hoki fishery is available 24 hours a day (A.N.D. Freeman pers. obs.).

Recent work on the Westland petrel's diet has shown that fisheries waste may form over $50 \%$ of the solid food brought back to the colony during the hoki fishing 
season (A.N.D. Freeman unpublished data). An unavoidable bias in diet sampling at seabird colonies is that the food consumed most recently can be over represented in the diet samples. In Procellariiformes, food is digested rapidly and converted to oil, so only the most recently ingested food is detected by diet sampling. As $68 \%$ of tracked flights stopped in the WCSI hoki fishery area in the twelve hours immediately prior to the bird's return to the colony, but on average birds only spent a third of their time in the vicinity of vessels, it is likely that diet sampling over estimated the importance of fisheries waste. The amount of time birds spent outside of the hoki fishing areas suggests that, despite the large scale fishery, Westland petrels continue to forage over much wider areas than those occupied by the hoki fishing fleets.

The methods of reporting fishing activity meant that there was no way of assessing the relationship of satellite tracked Westland petrels to other fisheries. Small fisheries of a few thousand tons for several species, including red cod Pseudophycis bachus, barracouta Thyrsites atun and ling Genypterus blacodes occur off the West Coast of the South Island (Annala \& Sullivan 1996), and Westland petrels also scavenge from these fisheries (A.N.D. Freeman unpublished data). Their importance to Westland petrels is unknown.

Unlike the foraging trips of pelagic species described by Weimerskirch et al. (1994a), the frequency distribution of Westland petrel foraging trips was unimodal, reflecting their shelf and slope foraging habits. Co-occurrence with fishing vessels was observed in trips of all durations and consequently, fisheries waste is probably important in both adult maintenance and chick provisioning. However, as most satellite tracked Westland petrels visited the WCSI hoki fishing fleet in the last 24 hours of their trips, the fishery may be most important in chick provisioning.

This research has shown that caution must be taken in interpreting satellite tracks as natural behaviour. Westland petrels carrying PTTs increased the length of their foraging trips markedly compared to birds that were not carrying transmitters. This is in contrast to satellite tracking studies on wandering albatross and light- 
mantled sooty albatross where transmitters were not considered to have altered the behaviour of the birds (Weimerskirch et al. 1993; Weimerskirch \& Robertson 1994), and radio tracking studies of Parkinson's petrel Procellaria parkinsoni, where comparisons of meal size and frequency between tracked and untracked birds suggested birds were foraging normally (Scofield, 1989). However, negative effects of tracking on foraging efficiency and speed have been noted in some other studies. For example attachment of PTTs during incubation significantly increased foraging trip duration in Adelie penguins (Clarke et al. 1994) and effects have been well documented in radio tracking studies on other bird taxa (eg. Gessaman \& Nagy 1988; Boag 1972). Other than increasing their foraging trip lengths, we cannot know whether or not satellite tracked Westland petrels behaved normally. Satellite tracking did not appear to have any adverse affect on adult weight or chick success.

\subsection{ACKNOWLEDGMENTS}

We are grateful for the help and company provided by the people who spent time with us on the colony during the tracking periods; Sue Waugh, Ami Kennedy, Jacqui Volmer and, especially, Alastair Freeman. Department of Conservation staff at Punakaiki provided accommodation and assistance in the field. We especially thank Deborah Carden and Chippy Wood for their support. The purchase of one PTT was funded by a New Zealand Lottery grant. Other PTTs were provided by D.G. Nicholls. The 1995 satellite tracking time was provided by NIWA; the 1996 tracking time was funded by the.Department of Conservation and Lincoln University. Without the skill of staff at Microwave Telemetry and Sirtrack Ltd, and their willingness to provide equipment suited to individual requirements, satellite tracking Westland petrels would not have been possible. Sira Ballara of NIWA provided invaluable help in the timely provision of the fisheries data. Andrew Ogilvie and Alastair Galbraith's alarm system allowed us to get some much valued sleep and shelter from inclement weather. John Baird and Bill Rosenberg of Lincoln Univerity advised on computer access to the satellite data, and Ryan Clements of Lincoln University advised on ArcView ${ }^{\circledR}$. Our thanks to them all. Finally, we thank Sandy Bartle for his support and advise throughout this and other components of our Westland petrel research. 


\subsection{REFERENCES CITED}

Abrams, R. W. 1983. Pelagic seabirds and trawl-fisheries in the Southern Benguela Current region. Marine Ecology Progress Series 11: 151-156.

Annala, J. H. \& Sullivan, K. J. (compilers) 1996. Report form the Fishery Assessment Plenary, April - May 1996: stock assessments and yield estimates. Science Policy, Ministry of Fisheries. Unpublished report held in NIWA library, Wellington. 308p.

Ayling, T. \& Cox, G. J. 1982. Collins Guide to the Sea Fishes of New Zealand. Revised edition. 343p.

Bartle, J. A. 1974. Seabirds of eastern Cook Strait, New Zealand, in autumn. Notornis 21: 135-166.

Bartle, J. A. 1985. Westland Black Petrel. In Complete Book of New Zealand Birds p. 91. Reader's Digest, Sydney.

Bartle, J. A. 1987. Westland Black Petrel research notes, 10-29/4/87. OSNZ News 44: 5.

Boag, D. A. 1972. Effect of radio packages on behaviour of captive Red grouse. Journal of Wildlife Management 36: 511-518.

Clarke, J.; Kerry, K. R.; Else, G. W. 1994. Monitoring Adelie penguin breeding and feeding ecology at Bechervaise Island, MacRobertson Land, Antarctica. Abstract in Workshop Report. Workshop on Researcher-Seabird Interactions, July 15-17, 1993, Monticello, Minnesota, USA. Washington.

Freeman, A. N. D; Nicholls, D. G.; Wilson, K-J.; Bartle, J. A. (in prep). The use of satellite tracking and radio tracking methods with Westland petrels (Procellaria westlandica). Submitted to Marine Ornithology.

Gessaman, J. A. \& Nagy, K. A. 1988. Transmitter loads affect the flight speed and metabolism of homing pigeons. The Condor 90: 662-668.

Imber, M. J. 1976. Comparison of prey of the black Procellaria petrels of New Zealand. New Zealand Journal of Marine and Freshwater Research 10: 119-130.

Jackson, S. 1988. Diets of the white-chinned petrel and sooty shearwater in the southern Benguela region, South Africa. The Condor 90: 20-28.

Langley, A. D. 1993. Spawning dynamics of hoki in the Hokitika Canyon. New Zealand Fisheries Technical Report No 34. 29p.

Mauck, R. A. \& Grubb, T. C. 1995. Petrel parents shunt all experimentally increased reproductive costs to their offspring. Animal Behaviour 49: 9991008. 
Ricklefs, R. E. 1983. Some considerations on the reproductive energetics of pelagic seabirds. Studies in Avian Biology 8: 84-94.

Scofield, R. P. 1989. Breeding biology and conservation of the Black petrel (Procellaria parkinsoni) on Great Barrier Island. Msc Thesis, University of Auckland.

Vooren, C. M. 1977. Sea bird observations off the West Coast of the South Island, New Zealand, October-November 1975. Notornis 24:137-139.

Walker, K.; Elliot, G.; Nicholls, D.; Murray, D.; Dilks, P. 1995. Satellite tracking of Wandering albatross (Diomedea exulans) from the Auckland Islands: preliminary results. Notornis 42: 127-137.

Warham, J. 1996. The behaviour, population biology and physiology of the petrels. Academic Press. 613p.

Weimerskirch, H.; Salamolard, M.; Sarrazin, F.; Jouventin, P. 1993. Foraging strategy of Wandering albatrosses through the breeding season: a study using satellite telemetry. The Auk 110: 325-342.

Weimerskirch, H. \& Robertson, G. 1994. Satellite tracking of light-mantled sooty albatrosses. Polar Biology 14: 123-126.

Weimerskirch, H.; Chastel, O.; Ackermann, L.; Chaurand, T.; Cuenot-Chaillet, F.; Hindermeyer, X.; Judas, J. 1994 a. Alternate long and short foraging trips in pelagic seabird parents. Animal Behaviour 47: 472-476.

Weimerskirch, H.; Doncaster, C. P.; Cuenot-Chaillet, F. 1994 b. Pelagic seabirds and the marine environment: foraging patterns of wandering albatrosses in relation to prey availability and distribution. Proceedings of the Royal Society of London 255: 91-97.

Wilson, R. P. \& Wilson, M-P. 1989. Tape: a package-attachment technique for penguins. Wildlife Society Bulletin 17: 77-79. 


\title{
Appendix 1.
}

\section{The use of Satellite Tracking and Radio Tracking Methods with Westland Petrels Procellaria westlandica}

\author{
A.N.D. Freeman ${ }^{1}$, D.G. Nicholls ${ }^{2}$, K-J. Wilson ${ }^{1}$, J.A. Bartle ${ }^{3}$ \\ ${ }^{1}$ Department of Entomology and Animal Ecology, PO Box 84, Lincoln University, \\ Canterbury, New Zealand. \\ ${ }^{2}$ Peninsula College of Technical and Further Education, Breeze Street, Carrum, \\ Victoria, 3196, Australia. \\ ${ }^{3}$ Museum of New Zealand Te Papa Tongarewa, PO Box 467, Wellington, \\ New Zealand
}

\section{Summary}

Two foraging trips of one female and one male Westland petrel Procellaria westlandica partially tracked by radio telemetry, and six foraging trips by three male Westland petrels tracked by satellite telemetry are reported. We report on the development of Platform Transmitting Terminals (PTTs) suitable for use on burrowing seabirds and on the successful deployment of the modified PTTs.

The birds tracked by VHF radio telemetry were recorded around the $200 \mathrm{~m}$ depth contour on a few days during their foraging trip but were beyond reception range most of the time. The birds tracked by satellite mostly foraged on the continental slope off the West Coast of the South Island except in one instance where a bird flew through Cook Strait and spent time on the Chatham Rise east of the South Island. The difficulties associated with interpreting satellite tracks for birds that travel relatively short distances at sea are discussed. 


\section{General Introduction}

Before 1958 the Westland petrel population was estimated to be between 3000 6000 birds (Jackson 1958). The total population (including non-breeders) is now estimated at 20000 (Marchant \& Higgins 1990). It has been suggested (Bartle 1985 1987) that this population growth was due to an increase in the food supply from offal and other waste discharged from fishing vessels, particularly in the hoki Macruronus novaezelandiae fishery which operates close to the Westland petrel's breeding grounds. However, little is known about the breeding season diet and foraging patterns of Westland petrels. The main aim of the radio and satellite tracking was to provide information on which fishing fleets are visited and the time spent foraging around fishing vessels compared to foraging naturally in other areas. This will be reported in subsequent papers.

Initially we attempted to determine foraging locations using VHF radio-tracking but a trial study in 1993 showed that Westland petrels forage beyond the range detectable with VHF technology. In 1995 two PTTs were used (provided by D.G. Nicholls) which were adapted for use with Westland petrels. This paper presents details of the VHF transmitter and PTT packaging, testing procedures and deployments, assessment of the effects transmitters have on Westland petrels and descriptions of the tracked flights. This paper is presented in two parts (a)VHF tracking and (b) satellite tracking.

\section{PART A Tracking Westland petrels with VHF transmitters}

\section{Introduction}

In 1993 Lincoln University established VHF radio receiver stations on Paparoa Peak (831m) near Greymouth, and Mt Rochfort (1038m) near Westport, to investigate movements of New Zealand fur seals Arctocephalus forsteri (Sinclair 1994). Theoretically, the maximum distances over which VHF signals could be 
received by the two stations were $125 \mathrm{~km}$ at Mt Rochfort and $112 \mathrm{kms}$ at Paparoa Peak (Sinclair 1994). This presented an opportunity to try radio-tracking Westland petrels, as their breeding colony is situated mid way between the two stations and the seal tracking coincided with the Westland petrel's breeding season. It was thought that breeding Westland petrels might forage within radio reception range.

\section{Methods}

On 8-9 July 1993, A.N.D. Freeman and J.A. Bartle with assistance from the Department of Conservation attached radio-transmitters to one female and three male Westland petrels at their breeding colony, near Punakaiki, West Coast, New Zealand. All birds were incubating eggs at the time of deployment. The transmitters were attached to the birds' backs with harnesses which had a weak link which would break if the bird became entangled (Karl \& Clout 1987). The dimensions of the VHF transmitters were $60 \mathrm{~mm} \times 38 \mathrm{~mm} \times 10 \mathrm{~mm}$. The transmitters weighed $35 \mathrm{~g}$ plus harness (total weight approximately $37 \mathrm{~g}$ ), and pulsed at 80 pulses per minute with a $30 \mathrm{~ms}$ pulse width. As the birds weighed between 1170 and $1380 \mathrm{~g}$ at the time of deployment, the transmitters were $2.7-3.2 \%$ of the birds' weight. The transmitters were powered by three LTC7PN cells and could have run for 31 days on continuous transmission. However, the birds were only monitored for 10 days because the seal tracking programme ended.

Tracking was carried out between 8 July - 18 July 1993. The Westland petrels could not be tracked continuously and were generally monitored at two to four hour intervals through the night and less often during the day. Transmitters could be detected while birds were in their burrows using a portable four element Yagi antenna and receiver up to $500 \mathrm{~m}$ away.

The bearings of signals received at the radio-tracking stations were plotted so that triangulated positions could be determined. At both stations mountain ranges limited the area over which signals could be received. The potential area of triangulation is shown in Fig 1. 


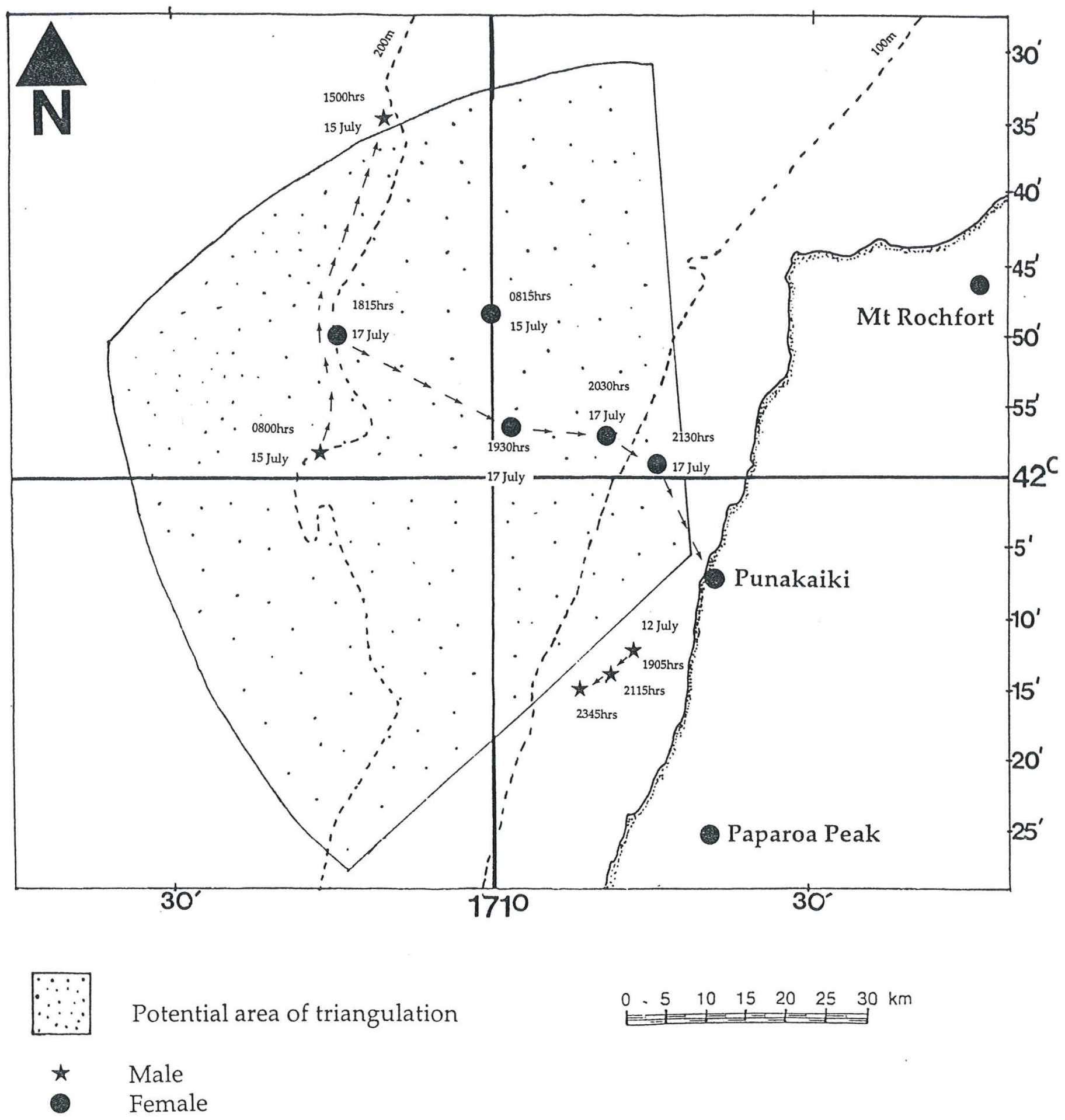

Figure 1. Locations of one male and one female Westland petrel radio-tracked in July 1993. 


\section{Results}

\section{Female ( Band Nos L30187/30188)}

This bird left the colony before dawn on 13 July but no signal was received from it until $0815 \mathrm{hrs}$ on $15 \mathrm{July}$ when it was $45 \mathrm{~km}$ north west of the colony. By the time of the next tracking session at $1500 \mathrm{hrs}$, the bird had again flown outside of radio reception range and was not located again until the evening of 17 July. During the evening of 17 July the bird was tracked from a position approximately $57 \mathrm{~km}$ north west of the colony to a position $24 \mathrm{~km}$ north west of the colony, presumably returning to its burrow (Fig. 1).

\section{Male 1 (Band Nos L 30189/30190)}

This bird left the colony before dawn on 12 July and clear signals were received at the Paparoa Peak station that evening. The strong signal at Paparoa Peak and the lack of signal at Mt Rochfort indicate that the bird was close inshore but outside the triangulation area. By 0545 hrs on 13 July, the bird had flown beyond radio reception range. No signal was received at $2200 \mathrm{hrs}$ on 14 July but at 0800hrs on 15 July, the bird was $52 \mathrm{~km}$ north west of the colony. At $1500 \mathrm{hrs}$ the bird had flown further north and the weak and intermittent signal indicated that it was on the edge of reception range about $100 \mathrm{~km}$ offshore. No further signals were received from this bird, which returned to the colony after 18 July (Fig. 1).

\section{Male 2 (Band Nos L30183/30184)}

This bird left the colony on 13 July and returned on 15 July without being detected by the radio receivers.

\section{Male 3 (Band Nos L23066/30161)}

This bird left the colony on 10 July and returned some time after 18 July when tracking had finished. It was not detected by the radio receivers.

When removing the transmitters from the birds we were concerned because the harnesses had tightened as the birds had increased in weight and girth during their foraging trips. As a result, we decided not to use harnesses in future studies of this species. Future telemetry studies of Procellariformes, which increase in 
girth during foraging trips, should consider this when determining the type and design of transmitter attachment.

\section{PART B Tracking Westland petrels with satellite transmitters}

\section{PTT design and testing}

Since radio telemetry was found to be unsatisfactory for tracking Westland petrels, satellite telemetry was subsequently used. At 28-30g the Microwave Telemetry Nano PTT was light enough to be carried by Westland petrels, but its standard shape $(65 \mathrm{~mm} \times 16 \mathrm{~mm} \times 16 \mathrm{~mm})$ was considered unsuitable for this species due to the height of the package (Fig. 2).

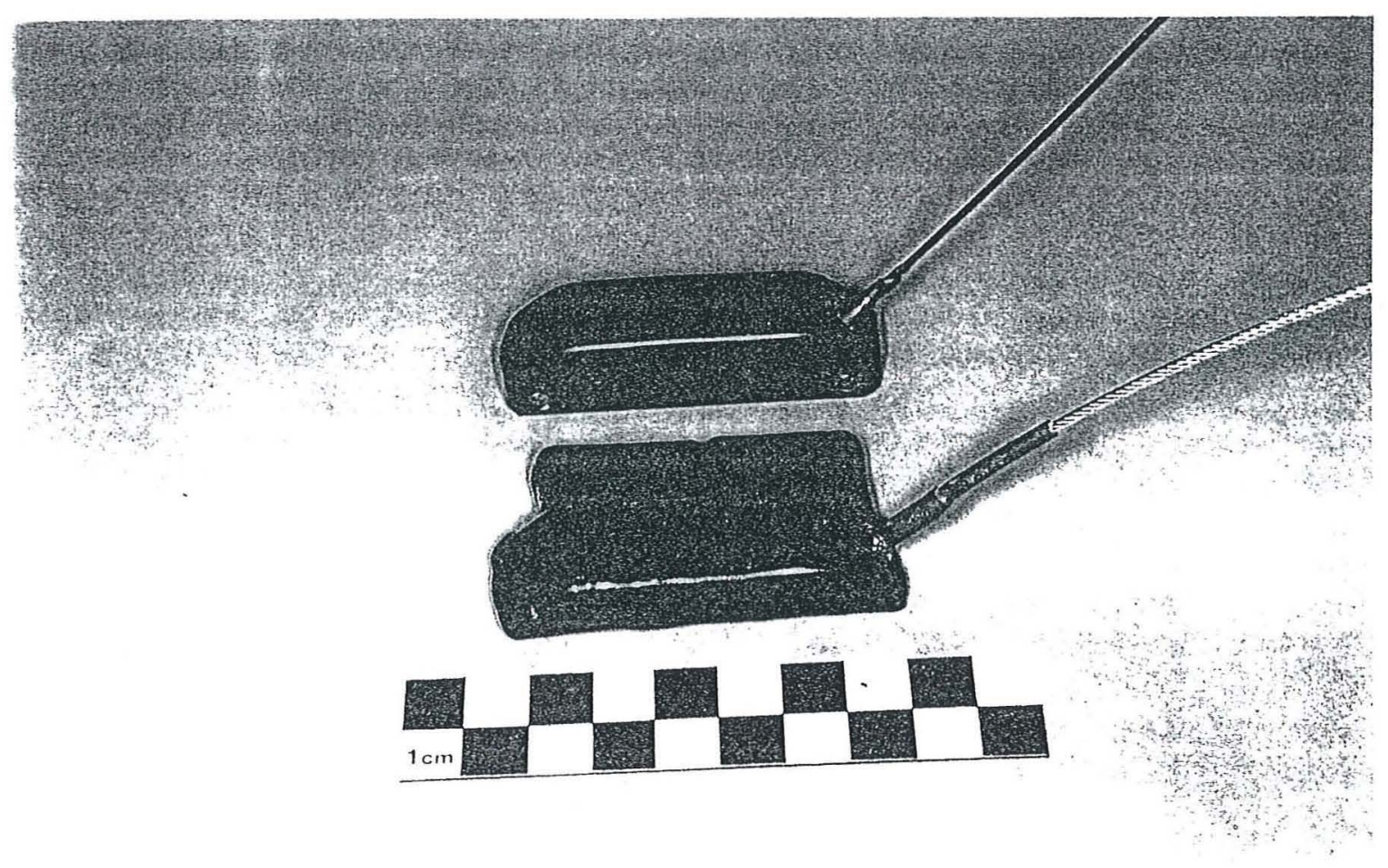

Figure 2. Standard shape Microwave Telemetry Nano PTT (above) and low profile Microwave Telemetry Nano PTT (below).

Westland petrels use burrows up to $2 \mathrm{~m}$ in length with entrances often only 15 $20 \mathrm{~cm}$ high into which birds must squeeze. We thought it necessary to use a PTT that would not hinder birds' access to their burrows, nor be susceptible to being 
scraped against the tunnel roof, or entangled in exposed roots in the burrow. Similarly, the PTT attachment needed to be designed so that birds could not become entangled in trees as they crash landed through the rain-forest canopy and tangled undergrowth on their return to the colony. Consequently, we designed a package which reduced the height of the PTT by placing the battery units alongside the transmitter instead of underneath it (maximum dimensions $=65 \mathrm{~mm}$ $\times 36 \mathrm{~mm} \times 10 \mathrm{~mm}$ ) (Fig. 2 ). A model of the new design was measured against Westland petrel study skins in Canterbury Museum to ensure that the width was not excessive. This new design had essentially the same dimensions as the VHF transmitters deployed successfully in 1993.

In June 1995 the two designs; the standard Microwave Telemetry shaped package and the new low profile package, were trialed by A.N.D. Freeman, deploying models on incubating birds. Accurately sized models of correct weight were constructed from balsa wood, lead shot and resin. The models were attached with tape to the backs of incubating birds; five flat models on 17 June 1995, and five standard shaped models on 20 June 1995. Scotch brand 471 plastic tape $(12 \mathrm{~mm}$ width) was used for the attachment, but this tape was not sufficiently sticky and probably contributed to the loss of three of the models at sea. Four of the models were removed before the birds went to sea; either due to time constraints, or because the attachment was no longer secure.

The Westland petrel's close relative, the White-chinned petrel Procellaria aequinoctialis, has been found to dive up to depths of 13m (Huin 1994). We anticipated that Westland petrels would dive to similar depths. Depth gauges were attached to the top of the models to test this. The gauges were lengths of clear plastic tubing with a dusting of icing sugar inside that recorded the maximum depth attained during deployment (Huin 1994, Burger \& Wilson 1988).

The results of the PTT model and maximum depth gauge deployments are shown in Table 1. The standard-shaped models proved unsuitable. Because of the height of the models, shortness of the bird's contour feathers, and rubbing against the 
roof of the burrow, these models soon pulled loose and pulled out feathers. Three were removed before the birds went to sea, and two birds returned from sea without the model PTTs. The new design was more successful, with only one model lost while the bird was at sea, probably due to failure of the tape.

Table 1. Employment and recovery of model PTTs on Westland petrels.

\begin{tabular}{|c|c|c|c|c|c|c|c|}
\hline $\begin{array}{l}\text { Model } \\
\text { Type }\end{array}$ & $\begin{array}{l}\text { Bird } \\
\text { Band } \\
\text { Number }\end{array}$ & Sex & $\begin{array}{l}\text { Fate of } \\
\text { model } \\
\text { PTT }\end{array}$ & $\begin{array}{l}\text { Trip } \\
\text { length } \\
\text { (days) }\end{array}$ & $\begin{array}{l}\text { Weight }(A) \\
\text { (grams) }\end{array}$ & $\begin{array}{l}\text { Weight }(R) \\
\text { (grams) }\end{array}$ & $\begin{array}{l}\text { Maximum } \\
\text { Depth (m) }\end{array}$ \\
\hline Standard & $\begin{array}{l}\text { L22276 } \\
\text { L16708 } \\
\text { L22160 } \\
\text { L14115 } \\
\text { L31715 }\end{array}$ & $\begin{array}{l}F \\
F \\
F \\
M \\
M\end{array}$ & $\begin{array}{l}\mathrm{L} \\
\mathrm{L} \\
\mathrm{R} \\
\mathrm{R} \\
\mathrm{R}\end{array}$ & $\begin{array}{l}5 \\
9-12\end{array}$ & $\begin{array}{l}1250 \\
1150 \\
1100 \\
1270 \\
1400\end{array}$ & & \\
\hline Modified & $\begin{array}{l}\text { L18650 } \\
\text { L14010 } \\
\text { L15770 } \\
\text { L13807 } \\
\text { L14293 }\end{array}$ & $\begin{array}{l}\mathrm{M} \\
\mathrm{M} \\
\mathrm{M} \\
\mathrm{M} \\
\mathrm{M}\end{array}$ & $\begin{array}{l}S \\
S \\
S \\
L \\
R\end{array}$ & $\begin{array}{l}2 \\
5 \\
11 \\
11+\end{array}$ & $\begin{array}{l}1250 \\
1400 \\
1350 \\
1300 \\
1450\end{array}$ & $\begin{array}{l}1300 \\
1400 \\
1300\end{array}$ & $\begin{array}{l}0.7 \\
1.4 \\
7.6\end{array}$ \\
\hline
\end{tabular}

$\mathrm{L}=$ lost during trip; $\mathrm{R}=$ removed before departure; $\mathrm{S}=$ secure on return. Weight $(\mathrm{A})=$ weight at attachment; Weight $(\mathrm{R})=$ weight on return.

The maximum depth recorded by the three recovered gauges was $7.6 \mathrm{~m}$. However, errors can occur with multiple immersions (as would be the case during foraging trips) and recovered tubes showed signs of moisture accumulation, another source of error (Burger \&Wilson 1988). Therefore, these results should be treated as indicative only. The real PTTs were pressure-tested to 10 metres.

The weights of the birds returning with model transmitters were close to their weights when the models were attached (Table 1). As birds did not depart immediately, they would have weighed less than shown when they left the colony. A return to their weight at the time of model attachment therefore indicates that they were able to feed successfully. 
The foraging trip lengths recorded for the birds returning with model transmitters ranged from 2 to 11 days. The birds that lost their model transmitters at sea are not included as it is not known when the loss occurred. Six foraging trips of birds without model transmitters, recorded during the same time period, also ranged from two days to more than 11 days suggesting that the model transmitters did not lengthen trip duration. Of the ten burrows in which an adult had a model transmitter fitted, nine hatched chicks (compared with overall hatching success in 1995 of $47 \%$ ) so the models are not thought to have affected hatching success.

\section{PTT deployment and satellite tracking}

\section{Methods}

Three male Westland petrels with chicks were tracked by satellite between 11 August and 19 September 1995. Dates and times of attachment and recovery are given in Table 2. Initially, we intended to compare foraging trips of both older and younger males and females. However, as foraging trips were longer than expected, with only two PTTs, this was unrealistic.

Two Microwave Telemetry Nano PTTs were packaged by Sirtrack Ltd to our low profile design described above (Fig. 2). The final weights of the packages were $36.7 \mathrm{~g}$ and $37.9 \mathrm{~g}$ ( 2.7 and $3.7 \%$ of the birds' weight). The PTTs were encased in black epoxy polymer, the antennae reinforced with polyurethane sealant and the completed units pressure-tested to $10 \mathrm{~m}$ depth. The time interval between transmissions was 70 seconds, a compromise between location accuracy and battery life. One PTT pulsed continuously for the 14 days it was deployed and the other PTT pulsed continuously for 14 days and was then programmed to a reduced duty cycle of 8 hours on , 17 hours off until its batteries ran out soon after recovery - a total of 41 days.

Strips of 10mm wide "Tesa" tape as recommended by Wilson \& Wilson (1989) were used for attaching the PTTs to the birds' back feathers between the wings. Two birds had no significant feather loss or damage resulting from the PTT attachment or recovery. The third had a small area of bare skin, about $1 \mathrm{~cm}^{2}$ 
underneath the PTT when it was removed after 33 days. All PTTs were still firmly attached when recovered.

Table 2. Deployment and recovery details of PTTs on Westland petrels.

\begin{tabular}{|c|c|c|c|c|}
\hline $\begin{array}{l}\text { Bird ID/ } \\
\text { flight }\end{array}$ & $\begin{array}{l}\text { Bird band } \\
\text { No. }\end{array}$ & $\begin{array}{l}\text { PTT attachment/ } \\
\text { recovery }\end{array}$ & Flight start/finish & $\begin{array}{l}\text { Trip length } \\
\text { (days) }\end{array}$ \\
\hline Paul/1 & L13807 & $11 / 8 / 951615 \mathrm{hrs} /$ & $\begin{array}{l}12 / 8 / 95 \text { before dawn/ } \\
16 / 8 / 951845 \mathrm{hrs}\end{array}$ & 5 \\
\hline Paul/2 & & $24 / 8 / 951850 \mathrm{hrs}$ & $\begin{array}{l}\text { 17/8/95 before dawn/ } \\
24 / 8 / 951850 \mathrm{hrs}\end{array}$ & 8 \\
\hline Sandy & L18650 & $\begin{array}{l}11 / 8 / 951655 \mathrm{hrs} / \\
16 / 8 / 950300 \mathrm{hrs}\end{array}$ & $\begin{array}{l}\text { 12/8/95 before dawn/ } \\
16 / 8 / 950300 \mathrm{hrs}\end{array}$ & 4 \\
\hline Spot/1 & L22370 & $17 / 8 / 951705 \mathrm{hrs}$ & $\begin{array}{l}\text { 18/8/95 before dawn/ } \\
31 / 8 / 95\end{array}$ & 14 \\
\hline Spot/2 & & & $\begin{array}{l}1 / 9 / 95 / \\
13 / 9 / 95\end{array}$ & 13 \\
\hline Spot/3 & & 19/9/95 1945hrs & $\begin{array}{l}\text { 15/9/95/ } \\
19 / 9 / 951945 \mathrm{hrs}\end{array}$ & 5 \\
\hline
\end{tabular}

Locations were obtained from the Argos system which records location with seven classes of accuracy: Classes $1-3$, less than $1 \mathrm{~km}$ error; Class 0 , above $1 \mathrm{~km}$ error; and Classes A, B and Z, accuracy not determined by Argos. The errors inherent in satellite location data for species tracked over relatively short distances presented us with problems of how to process and display these data objectively. After considering several alternatives, all classes of positions were plotted and a smoothing algorithm fitted. The smoothing algorithm plotted satellite fixes of known accuracy and substituted a weighted running average for the remaining points. The weightings used were 0.2 for classes $Z, A$ and B; 1 for class 0 and 10 for classes 1,2 and 3. The smoothing algorithm took into account what was known about the accuracy of the previous and next positions to objectively plot points of unknown accuracy. The equation applied to these points was:

(prior position $\times$ weight $)+2$ (present position $x$ weight $)+($ next position $\times$ weight $)$ weight $_{\text {previous }}+2$ weight $_{\text {present }}+$ weight $_{\text {next }}$ 
The effect of the smoothing algorithm can be seen by comparing the points received from Argos with the flight paths derived from the algorithm (Figs. 3-5).

A radio receiver (model AOR 1500) was used in the later stages of tracking to detect when the last bird tracked was close to, or had returned to, the colony. Signals were received from the PTT the night before the bird returned to shore. However, as the PTT was on a reduced duty cycle and was not transmitting when the bird returned, it is not known whether or not the receiver would have detected the bird's return. After the PTT was recovered and was next transmitting it was placed in several different burrows to test whether the receiver could detect PTTs on birds in burrows from the campsite (up to $200 \mathrm{~m}$ away). In all cases clear signals were received.

\section{Results}

Paul (Band No L13807), an experienced breeding male first banded in 1970, left the colony on his first tracked foraging trip before dawn on 12 August 1995 and returned to the colony on the evening of 16 August 1995. During that time, Paul's locations were concentrated in two areas $90 \mathrm{~km}$ north-west and $80 \mathrm{~km}$ west of the colony; $41^{\circ} 30^{\prime} \mathrm{S}, 170^{\circ} 40^{\prime} \mathrm{E}$ and $42^{\circ} 10^{\prime} \mathrm{S}, 170^{\circ} 20^{\prime} \mathrm{E}$ on the continental slope. Paul was tracked for a second flight on which he departed before dawn on 17 August 1995 and returned on the evening of 24 August 1995. On Paul's second trip, he travelled south-west and locations were concentrated $150 \mathrm{~km}$ south-west of the colony at $42^{\circ} 30^{\prime} \mathrm{S}, 170^{\circ} 10^{\prime} \mathrm{E}$ and as far as $300 \mathrm{~km}$ south-west at $43^{\circ} 40^{\prime} \mathrm{S}, 169^{\circ} 10^{\prime} \mathrm{E}$ also on the continental slope (Fig. 3).

Sandy (Band No L 18650), a 17yr old male that had bred only once since 1991, left the colony before dawn on 12 August 1995 and returned at 3am on 16 August. During his foraging trip, locations were concentrated at $42^{\circ} 20^{\prime} \mathrm{S}, 170^{\circ} 20^{\prime} \mathrm{E}$ but also covered areas south west and west of the colony between approximately $41^{\circ} 40^{\prime} \mathrm{S}$ and $43^{\circ} \mathrm{S}$ and $169^{\circ} 20^{\prime} \mathrm{E}$ and $171^{\circ} \mathrm{E}$. Most positions were on the continental slope (Fig. 4). 
Spot (Band No L 22370), a male of unknown age, left the colony before dawn on 18 August 1995 and was not recaptured until 19 September 1995. However, because his burrow was not monitored constantly over that period, there are two occasions when the satellite data suggests he returned to his burrow; 31 August 1995 and 13-15 September 1995. The period 18 August - 19 September is therefore assumed to cover three foraging trips; 18-31 August, 1-13 September and 15-19 September.

Spot spent the first two days of his first foraging trip north-west of the colony. Locations received were concentrated in the area $41^{\circ} 30^{\prime} \mathrm{S}, 170^{\circ} 30^{\prime} \mathrm{E}$. Spot then flew rapidly through Cook Strait on 20 August and spent until 25 August in Cook Strait and on the eastern edge of the Chatham Rise. His homeward flight took him back through Cook Strait on 26 August and by 27 August he was close inshore in the Karamea Bight. He then returned to the area in which he had spent the first two days of his trip and from there he is presumed to have returned to the colony for not more than two hours on 31 August. Two hours was the maximum time between checks of Spots' burrow on that night.

On Spot's second foraging trip he flew in large circles west of the colony on the continental slope. He is presumed to have spent the nights of 13 and 14 September ashore, departing again on 15 September. He visited the same area of the continental slope during his third foraging trip and returned to the colony on the evening of 19 September (Fig. 5).

All three birds increased in weight between PTT attachment and recovery indicating that they fed successfully during their foraging trips (Table 2). Their foraging trips ranged in length from four to fourteen days and were comparable with the highly variable trip lengths recorded for untracked birds in other burrows. Eighteen foraging trips by other male and female Westland petrels monitored during August and September 1995 ranged in length from 1day to at least 9 days ( 2 birds had been absent for 9 days when monitoring stopped). All three satellite tracked birds had chicks approaching fledging when their burrows were inspected on 15 November 1995. 


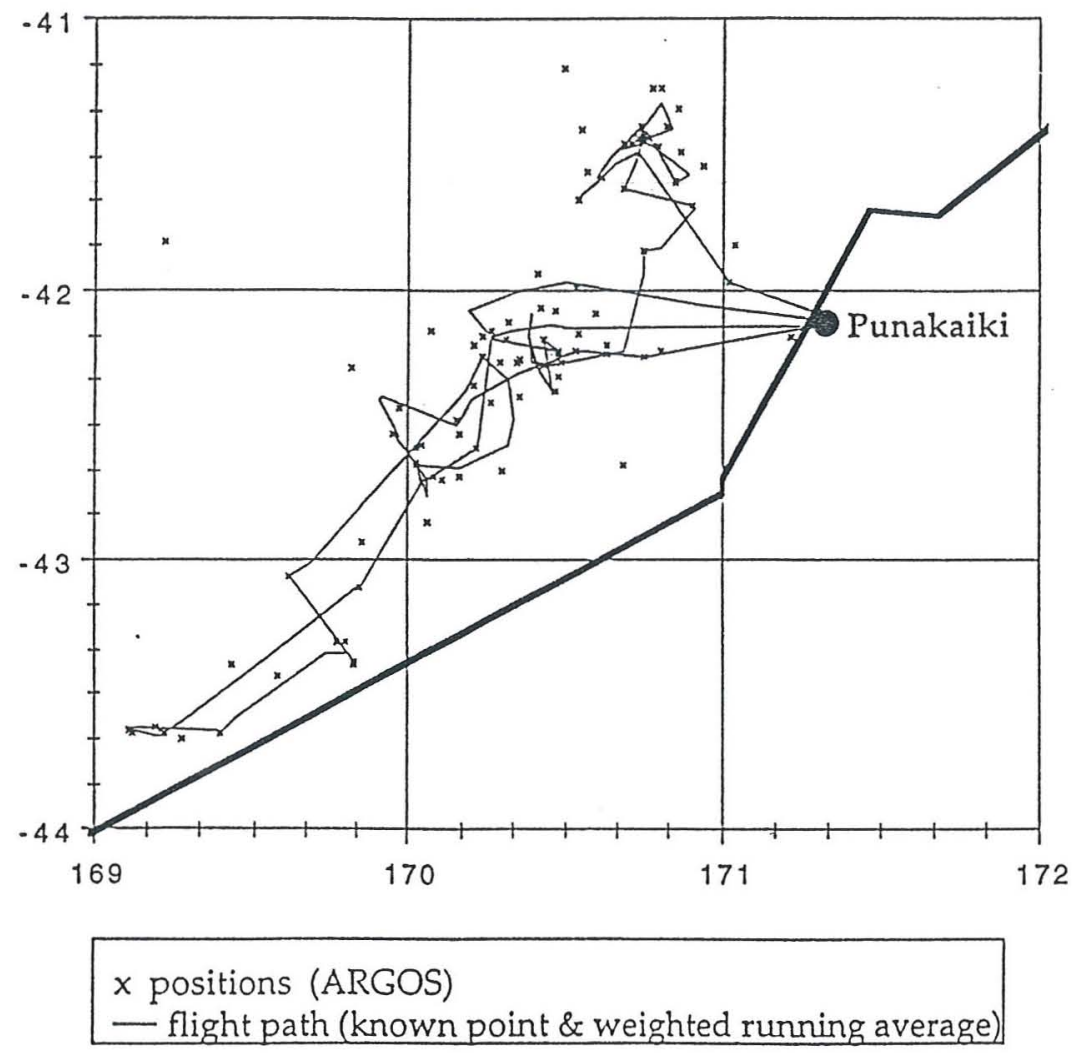

Figure 3. Satellite tracks of Paul 12 - 16 August 1995.

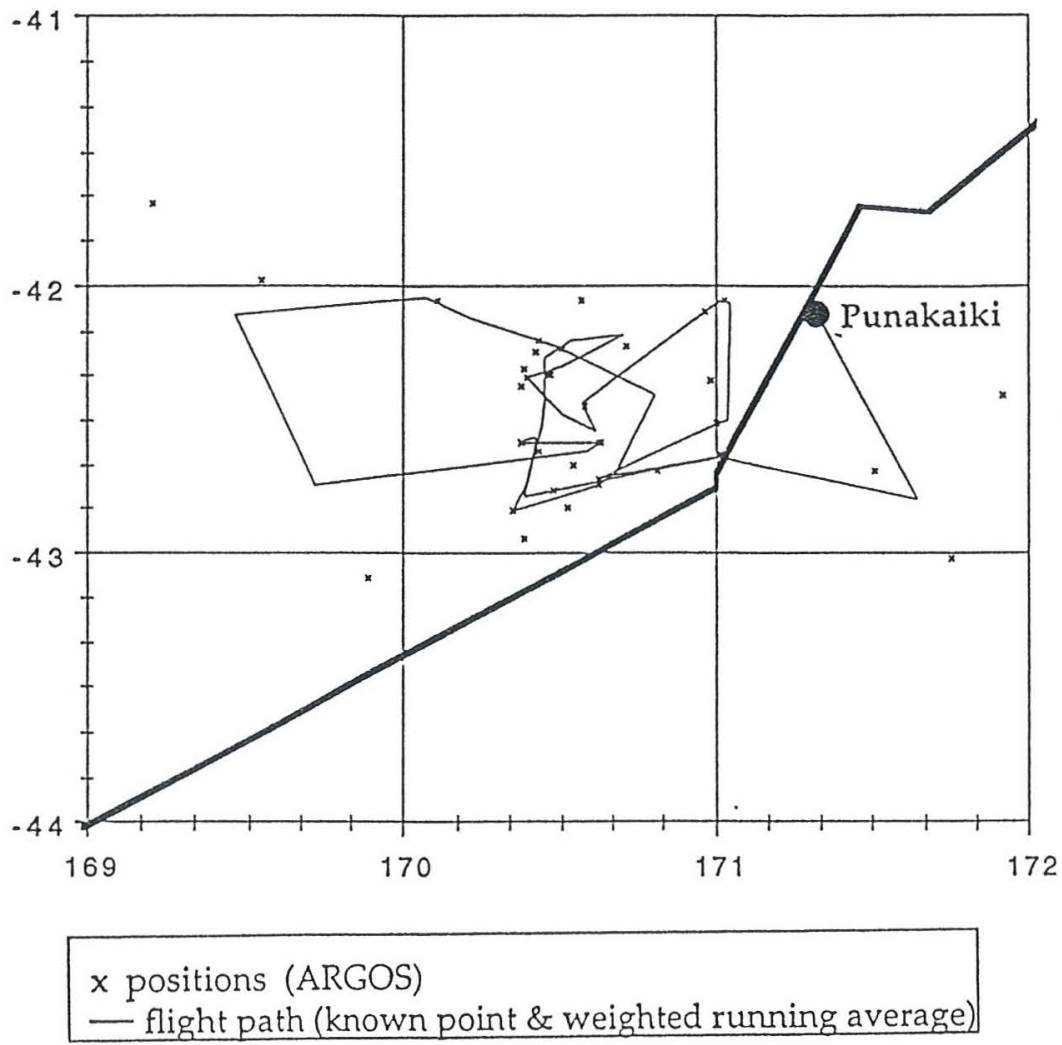

Figure 4. Satellite track of Sandy 12 - 16 August 1995. 


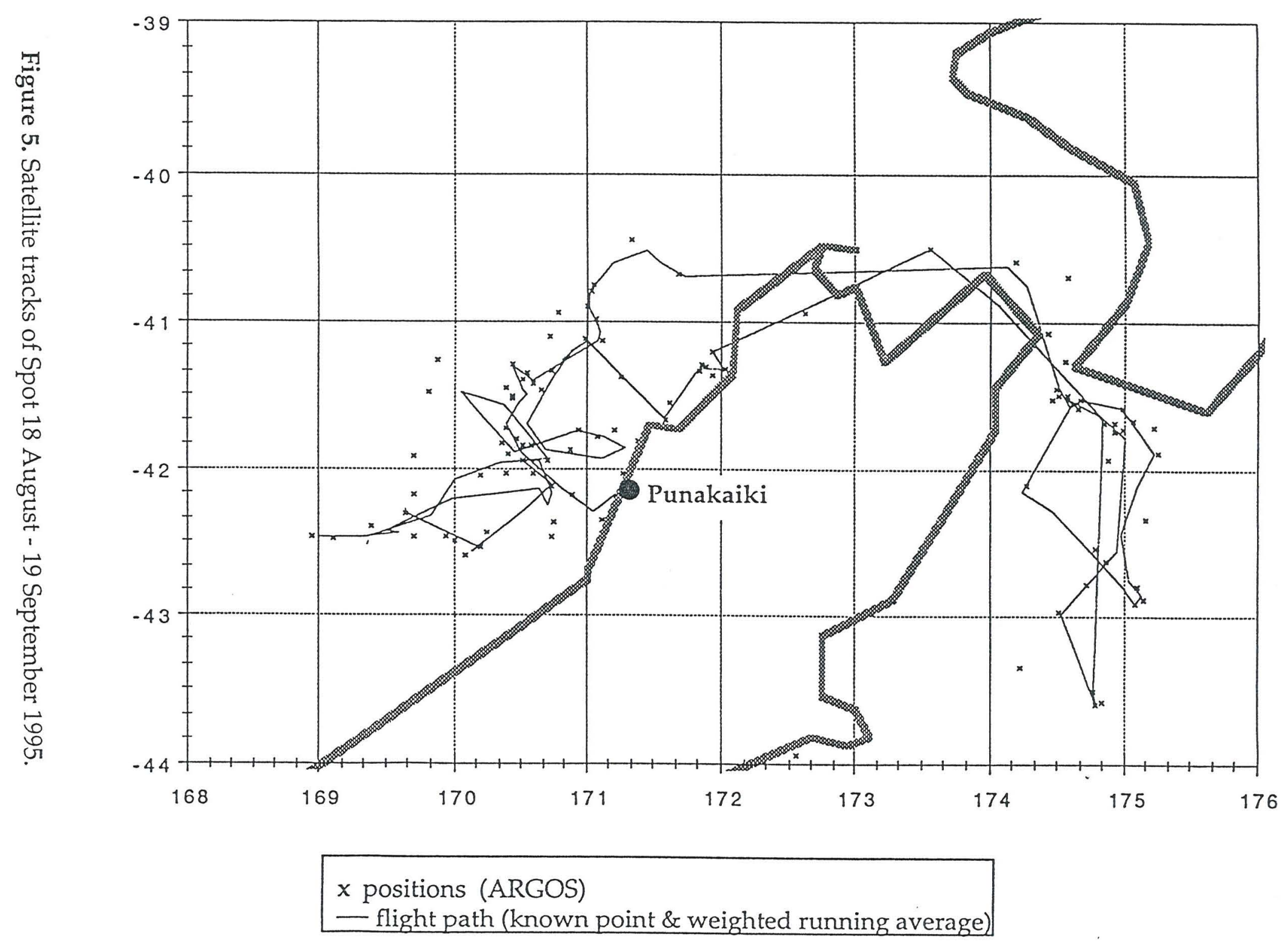




\section{Discussion}

Both of the birds tracked by VHF radio telemetry were recorded around the $200 \mathrm{~m}$ depth contour on a few days during their foraging trip but were beyond reception range most of the time. From what is known of Westland petrel distribution at sea, and has now been shown by satellite tracking, it is possible that birds were feeding on the continental slope, outside of radio reception range, during the times that signals were not received.

Although the theoretical range of the radio tracking equipment was about $100 \mathrm{~km}$, it is possible that factors such as weather conditions and interference reduced signal quality and the distance over which signals could be received (Sinclair 1994). At short distances, however, signals were strong (A.B. Freeman pers. comm.), and as all transmitters were still functioning when recovered, we are confident that signals could be received whenever the birds were within range. The distances over which Westland petrels forage during incubation made VHF radio telemetry unsatisfactory for tracking them.

The satellite-tracked flights reported here are the first recorded for a petrel smaller than an albatross, mollymawk or giant petrel. The results confirm the impression, gained during radio-tracking, of the importance of the continental slope to breeding Westland petrels. They also show that a breeding bird can complete a long distance flight ranging as much as $800 \mathrm{~km}$ from the colony.

Experiments with model PTTs showed that a low profile PTT package is necessary for burrowing birds to prevent damage from the burrow roof and to provide an adequate attachment for birds with short contour feathers. Attaching the PTTs with tape provided a secure attachment that was quick and easy to apply and remove. Tape is considered preferable to the harnesses which became tight at the end of foraging trips and had the risk of snagging in vegetation.

The majority of positions received from ARGOS for birds in this study were of unknown accuracy. Over the relatively short distances breeding Westland petrels 
fly, location errors are likely to be significant and will limit our ability to relate locations to fishing activity, one of the objectives of this study that will be reported in a subsequent paper. These inaccuracies also mean that estimates of distance and direction between successive points are dubious; and the number of knownaccuracy points were too few to calculate flight speed. Applying an algorithm that uses what is known about the accuracy of previous and next positions to plot points of unknown accuracy provides an objective way to smooth and interpret the flight paths.

Delays of several hours often occur between satellite fixes and the data becoming available. For our Westland petrel tracking this meant that we had to maintain a watch over bird's burrows each night in order to be sure of recapturing birds as the satellite data was not current enough to give early warning of a bird's return. Maintaining a constant watch was not feasible due to weather conditions and time constraints and so we appear to have missed two of Spot's returns to the colony. Use of a hand-held AOR 1500 receiver on the colony can alleviate this problem by making detection possible from a campsite.

Our study has shown that satellite tracking can provide useful data on general foraging areas and patterns of a Procellariidae seabird which was not achievable using VHF radio tracking.

\section{Acknowledgments}

The satellite time was provided by Paul Sagar and the National Institute of Water and Atmospheric Research. The Department of Conservation funded the VHF tracking and provided logistical support. Broadcast Communications Ltd provided facilities for the VHF tracking stations. Support in the field was provided by Alastair Freeman, Jonathan Sinclair, Les van Dijk, Craig Murdoch, Kevin Field, Doug Cairns, Susan Waugh, Frances Schmecel and Phillipa Gardner. Geoff Tunnicliffe of Canterbury Museum gave access to museum specimens. Kevin Lay of Sirtrack Ltd. provided advice and we are grateful for the experience of Albatross Research La Trobe University with telemetry. John Baird and Bill Rosenberg of Lincoln University advised on computer access to the satellite data. 


\section{References Cited}

Bartle, J.A. 1985. Westland black petrel. In Complete Book of New Zealand Birds p.91. Reader's Digest, Sydney.

Bartle, J.A. 1987. Westland black petrel research notes, 10-29/4/87. OSNZ News 44: 5.

Burger, A.E. \& Wilson, R.P. 1988. Capillary-tube depth gauges for diving animals: An assessment of their accuracy and applicability. Journal of Field, Ornithology 59: 345-354.

Huin, N. 1994. Diving depths of White-chinned petrels. Condor 96: 1111-1113.

Jackson, R. 1958. The Westland petrel. Notornis 7: 230-233.

Karl, B.J. \& Clout, M.N. 1987. An improved radio transmitter harness with a weak link to prevent snagging. Journal of Field Ornithology 58: 73-77.

Marchant, S. \& Higgins, P.J. 1990. Handbook of Australian, New Zealand and Antarctic birds. Vol.1 Ratites to Petrels. Melbourne, Oxford University Press.

Sinclair, J.G. 1994. The seasonal movements and foraging ecology of female New Zealand fur seals, Arctocephalus forsteri, (Lesson, 1828) from Cape Foulwind, Westland, New Zealand. M.Appl.Sc. Thesis. Lincoln University.

Wilson, R.P. \& Wilson, M-P. 1989. Tape: a package-attachment technique for penguins. Wildlife Society Bulletin 17: 77-79. 